\title{
Soilless Substrate Hydrology Can Be Engineered to Influence Plant Water Status for an Ornamental Containerized Crop Grown within Optimal Water Potentials
}

\author{
Jeb S. Fields ${ }^{1}$ \\ LSU AgCenter, Louisiana State University, Hammond Research Station, 21549 Old Covington \\ Highway, Hammond, LA 70403
}

James S. Owen, Jr. ${ }^{2,5}$

Department of Horticulture, Virginia Tech, Hampton Roads Agricultural Research and Extension Center, 1444 Diamond Springs Road, Virginia Beach, VA 23455

James E. Altland ${ }^{3}$

Application Technology Research Unit, USDA-ARS, Agricultural Engineering Building, 1680

Madison Avenue, Wooster, $\mathrm{OH} 44691$

\author{
Marc W. van Iersel ${ }^{4}$ \\ Department of Horticulture, University of Georgia, 1111 Plant Science Building, 120 Carlton Street, \\ Athens, GA 30602 \\ Brian E. Jackson ${ }^{2}$ \\ Department of Horticultural Science, North Carolina State University, 130 Kilgore Hall, Raleigh, NC \\ 27695
}

\begin{abstract}
Additional INDEX words. available water, coir, Hibiscus, hydraulic conductivity, pine bark, pore size, sphagnum peat
Abstract. Water-efficient soilless substrates need to be engineered to address diminishing water resources. Therefore, we investigated soilless substrates with varying hydrologies to determine their influence on crop growth and plant water status. Aged loblolly pine (Pinus taeda) bark was graded into four particle size fractions. The coarsest fraction was also blended with either sphagnum peat or coir at rates that mimic static physical properties of the unfractionated bark or conventional substrate used by specialty crop producers within the eastern United States. Hibiscus rosasinensis 'Fort Myers' plugs were established in each of the seven substrates and maintained at optimal substrate water potentials $(-50$ to $-100 \mathrm{hPa})$. After a salable crop was produced 93 days after transplanting, substrate was allowed to dry until plants completely wilted. Crop morphology and water use was affected by substrate hydrology. Increased substrate unsaturated hydraulic conductivity $(K)$ allowed for plants to access higher proportions of water and therefore increased crop growth. Maintaining optimal substrate water potential allowed plants to be produced with $<18 \mathrm{~L}$ water. Measurements of plant water availability showed that the substrate water potential at which the crop ceases to withdraw water varied among substrates. Pore uniformity and connectivity could be increased by both fibrous additions and particle fractionation, which resulted in increased substrate hydraulic conductivity $\left(K_{\text {s }}\right)$. Plants grown in substrates with higher hydraulic conductivities were able to use more water. Soilless substrate hydrology can be modified and used in concert with more efficient irrigation systems to provide more water sustainability in container crop systems.
\end{abstract}

Received for publication 30 Aug. 2017. Accepted for publication 8 June 2018. Funding for this work was provided, in part, by the Virginia Agricultural Experiment Station and the Hatch Program of the National Institute of Food and Agriculture (SCRI 2014-51181-22372), U.S. Department of Agriculture.

A special thanks to Joshua Heitman and Holly Scoggins for comprehensive review of the manuscript herein. We would also like to thank Pacific Organics and Fibre Dust LLC for supplying materials used in this research.

Trade or brand names used in this publication does not constitute a guarantee or warranty of the product by Virginia Tech and does not imply its approval to the exclusion of other products or vendors that also may be suitable.

${ }^{1}$ Assistant Professor.

${ }^{2}$ Associate Professor

${ }^{3}$ Research Horticulturist.

${ }^{4}$ Professor.

${ }^{5}$ Corresponding author. E-mail: jsowen@vt.edu.
The majority of all specialty crops spend a portion of their lifecycle in a container which uses soilless substrates. About $66 \%$ of the total $\$ 13$ billion in annual greenhouse, floriculture, nursery crops sold annually were produced in containers within the United States (U.S. Department of Agriculture, 2015). Soilless substrates were first introduced for container crop production to increase drainage by maintaining a relatively large proportion of air-filled porosity (AS) as compared with previously used mineral soils (Raviv and Lieth, 2008). These highly porous, initially disease-free, substrates have been designed to ensure ample drainage regardless of irrigation practices or precipitation to prevent hypoxic conditions. This has led to a practice of excess water application to eliminate any 
risk of under-watering (Mathers et al., 2005). Moreover, this excess water application leads to inefficient use of water resources and subsequent leaching or runoff of applied agrichemicals (Million et al., 2007).

Freshwater is a finite resource, in which $\approx 70 \%$ of the freshwater consumed in the world is used for agricultural purposes and nearly $40 \%$ of the freshwater withdrawn in the United States is used to irrigate crops (Kenney et al., 2009). Fulcher and Fernandez (2013) reported that nurseries that produce containerized woody ornamentals apply water upward of $177.3 \mathrm{~m}^{3} \cdot \mathrm{ha}^{-1} \cdot \mathrm{d}^{-1}$ during the periods of high water demand.

Containerized specialty crop producers continue to be more conscientious of water use, whether it is due to economic decisions, governmental restrictions, or increased environmental stewardship (Fulcher et al., 2016) but only innovators or early adopters have only begun to take large steps to implement water saving practices. Varied efforts to reduce the water load in ornamental container production include different irrigation schemes (Warsaw et al., 2009), crop water use modeling (Million et al., 2010), crop spacing and arrangement variation (Beeson and Yeager, 2003), and sensor driven irrigation (Chappell et al., 2013), albeit without a clear alternative to overhead irrigation in container nursery production (Fulcher et al., 2016). About 50\% of container nurseries currently use overhead irrigation, without the capability of using more sustainable irrigation delivery methods (Beeson et al., 2004). Further water savings could be realized through reengineering soilless substrates with increased $K$, coupled with reduced irrigation, to increase water efficiency of containerized specialty crop production. Therefore, research should, in part, move toward engineering new soilless substrates to increase water resource efficiency.

Current best management practices (Bilderback et al., 2013) for container production of ornamental nursery crops in the southeastern United States recommend static physical properties with a large proportion of $\mathrm{AS}(10 \%$ to $30 \%)$ at container capacity [CC (45\% to $65 \%)$ ]. Instead of solely using recommended static measures (AS and $\mathrm{CC}$ ), dynamic hydraulic properties, including the inherent relationship between volumetric water content $(\Theta)$, water potential $(\Psi)$, and $K$, can provide greater insight in determining suitability of soilless substrates (Caron et al., 2014). Moisture characteristic curves (MCCs), which represent the relationship between $\theta$ and $\Psi$ of a porous media are used by researchers to not only determine static physical properties (Milks et al., 1989), but also provide information regarding degree of water availability (de Boodt and Verdonck, 1972) and infer pore structure (Drzal et al., 1999).

Campbell and Campbell (1982) discussed the importance of high $K$ to allow roots to access water from greater distances within mineral soil matrices. da Silva et al. (1993) discussed the merits of measuring $K$ in soilless substrates primarily composed of sphagnum peat to create more efficient irrigation scheduling to help reduce water stress. Raviv et al. (1999) deemed decreasing $K$ as the primary limiting factor for water uptake by roots in soilless substrates; however, they noted that in situ measurements of substrate $K$ are not easily obtained and relationships between $K$ and $\Theta$ or substrate $\Psi$ should be better understood to make predictions of water availability in containers. Researchers have observed minimal reductions in substrate $\theta$ can result in great reductions in unsaturated $K$ (Wallach et al., 1992). These changes become more pronounced as $\theta$ decreases further away from saturation in peat-based substrates (O'Meara et al., 2014).

The overarching objective of this research is to determine if basic modifications of soilless substrate hydrophysical properties can increase water retention or enhance root accessibility of substrate water and subsequently increase crop water efficiency while retaining or improving crop growth. This objective was accomplished by 1) determining the influence of substrate modifications on hydraulic properties, 2) assessing the effects of substrate hydraulic properties on water dynamics for crops grown in optimal substrate water potentials (between -50 and $-100 \mathrm{hPa}$ ), and 3) measuring how water availability for a containerized crop is affected by varying hydraulic properties.

\section{Materials and Methods}

Substrate Preparation. On 17 Mar. $2015, \approx 2.5 \mathrm{~m}^{3}$ of stabilized (aged between 4 and 6 months) loblolly pine bark screened through a $12.6-\mathrm{mm}$ screen was attained from a commercial nursery substrate company (Pacific Organics, Henderson, NC). The bark was further separated into four different size fractions by sieving through a shaker rotating at $\approx 8$ oscillations/s (Custom Fabricated Shaker; Steve's Welding, Williamston, SC) with 6.3-, 4.0-, and 2.3-mm screens (W.S. Tyler, Mentor, OH) at the Substrates Processing and Research Center located at North Carolina State University, Raleigh. The sieve sizes used in this research were chosen based on preliminary experimentation to provide four unique fractions. The process entailed incrementally placing $\approx 0.05 \mathrm{~m}^{3}$ of pine bark $(64.6 \% \pm 0.8 \%$ moisture content measured via random sampling throughout the screening process) into the shaker tray, smoothing the pine bark to an even depth of $\approx 6 \mathrm{~cm}$, shaking through a $6.3-\mathrm{mm}$ screen for $90 \mathrm{~s}$, and then placing particles that did not pass $(\geq 6.3 \mathrm{~mm})$ and which passed through $(<6.3 \mathrm{~mm})$ the screen into separate $0.19-\mathrm{m}^{3}$ drums. Once $0.38 \mathrm{~m}^{3}$ of each substrate was collected, the process was repeated on the bark that passed through the initial screen using 4.0- and 2.3-mm screens to collect $0.19 \mathrm{~m}^{3}$ of each size fraction. This process resulted in four particle size fractions of pine bark: $>6.3 \mathrm{~mm}(\mathrm{PF} 6), 4.0-$ $6.3 \mathrm{~mm}$ (PF4), 2.3-4.0 mm (PF2), and $\leq 2.3 \mathrm{~mm}$ (PF0). In addition, $0.38 \mathrm{~m}^{3}$ of unprocessed pine bark (UPB) was placed in sealed drums for later use. All substrates were then transported to the Virginia Tech Hampton Roads Agricultural Research and Extension Center in Virginia Beach for analysis and experimentation.

Compressed bales of sphagnum peat (Fafard, Agawam, MA) and coir (FibreDust LLC, Glastonbury, CT) were hydrated, reconstituted, and stored individually in sealed plastic tubs for $24 \mathrm{~h}$ to allow for moisture equilibrium. Peat and coir were blended with PF6 to produce two additional substrates: $65 \%$ (by volume) PF6: 35\% (by volume) peat (P35) and 60\% (by volume) PF6: 40\% (by volume) coir (C40) with the goal of mimicking the static physical properties [CC, AS, and total porosity (TP)] of UPB. Incorporating the peat and coir into the bark substrate shifted most substrate particles $<6.3 \mathrm{~mm}$ from platy in texture (typical of pine bark particles) to a more fibrous texture (sphagnum peat and coir), and thus, affecting pore connectivity and subsequent water movement or availability.

Static Physical Properties. Porometer analysis (Fonteno and Harden, 2010) was conducted to determine static physical properties, including AS, CC, TP, and bulk density (Db), for each of the seven substrates. Particle size distributions of three 
replications for each substrate were then determined by shaking $100 \mathrm{~g}$ of oven dried substrate for $5 \mathrm{~min}$ with a shaker (Ro-Tap Rx-29; W.S. Tyler) equipped with 6.30-, 2.00-, 0.71-, 0.50-, $0.25-$, and $0.11-\mathrm{mm}$ sieve and a pan. Particles remaining on each sieve or in the pan after agitation were used to determine particle size distribution by weight. The particles sizes were then grouped into three texture classes based on particle diameter including large $(>2.00 \mathrm{~mm})$, medium (between 2.00 and $0.71 \mathrm{~cm})$, and small $(<0.71 \mathrm{~cm})$.

Hydraulic Properties. Saturated hydraulic conductivity measurements were attained on three replications of each of the seven substrates using a commercial research system (KSAT; Decagon Devices, Pullman, WA). This measurement consisted of packing each substrate into three aluminum cores $\left(250 \mathrm{~cm}^{3}\right)$ using an assembled column (lower $250-\mathrm{cm}^{3}$ core attached below the sample core, with two further $250-\mathrm{cm}^{3}$ cores fixed above the sampling core) that was filled to the top, lifted, and dropped from $5 \mathrm{~cm}$ height five times. This ensured constant $\mathrm{Db}$ for each individual substrate throughout all laboratory analyses. The bottom of each packed core was covered with cheesecloth, placed into a plastic tub, saturated in incremental stages in which the water table was raised from the bottom, and left for $24 \mathrm{~h}$ to equilibrate. After equilibration, sample cores were affixed with a collar and appropriate upper and lower screen (all included with the KSAT device) to prevent particles from escaping and ensuring all water was passed through the substrate instead of passing outside of the core. Samples were then affixed into the KSAT device and were again saturated from the base to replace any water lost during preparation. Using the KSAT device, $K_{\mathrm{s}}$ was measured for each replication three consecutive times in the constant head measurement mode before being removed from the device.

Volumetric water content $(\theta)$ of each substrate was measured at low $\Psi(<-10,000 \mathrm{hPa}$ or $-1.0 \mathrm{MPa})$ via a dewpoint hygrometer (WP4C; Decagon Devices), following procedures described by Fields (2013). Stainless steel sampling dishes (Decagon Devices) were filled about half way ( $\approx 5 \mathrm{~mm}$ depth) to completely cover the bottom surface of the dish and allowed to air dry for differing amounts of time to result to varying degrees of dryness or moisture content before measurement. Each dish was then sealed in the drawer of the dewpoint hygrometer and $\Psi$ was measured in "Precise Mode." After measurement, the dishes were removed and immediately weighed, and dried in a forced-air drying oven at $105^{\circ} \mathrm{C}$ for $48 \mathrm{~h}$. This process was repeated until seven measurements between -1.0 and $-3.0 \mathrm{MPa}$ were attained. The $\theta$ of the samples were calculated using measured $\mathrm{Db}$ to provide the substrate $\theta$ within the $\Psi$ range.

Moisture characteristic curves were developed for each of the seven substrates $(n=1)$ via the evaporative method (Hyprop; UMS, Munich, Germany) following the procedures described by Fields et al. (2016). Each substrate was packed to the same $\mathrm{Db}$ as for porometer analysis to ensure uniformity and mimic substrates in planted containers. Along with the relationship between $\Theta$ and $\Psi$, the evaporative method provides measurements of the functions $K(\Theta)$ and $K(\Psi)$ for a given porous media. Data for each substrate were then compiled with software (HypropFit; UMS), along with values $<-1.0 \mathrm{MPa}$ (from dewpoint hygrometry) and TP (from porometer). With these added points included, data were then modeled (SAS version 9.3; SAS Institute, Cary, NC), to fit the Brooks and Corey (1964) moisture tension model:

$$
\text { Brooks and Corey model }: S \mathrm{e}=\left\{\begin{array}{c}
1, \text { if } h \leq H_{\mathrm{b}} \\
\left(\frac{h}{H_{\mathrm{b}}}\right)^{-\lambda}, \text { if } h>H_{\mathrm{b}}
\end{array}\right.
$$

where $S \mathrm{e}=\left(\frac{\theta-\theta_{r}}{\theta_{s}-\theta_{r}}\right)$, or effective saturation, and $h$ is substrate tension $(-\mathrm{hPa})$. Fitting parameters within the model are measures of pore size distribution uniformity $\{\lambda$ [unit-less parameter to infer relative pore size uniformity (Brooks and Corey, 1964)]\} and air entry point $\left(H_{\mathrm{b}}\right)$ that provide more information toward substrate hydraulic properties than other models. Other parameters include $\theta_{s}$, which is the $\theta$ at saturation, and $\Theta_{r}$, which is the $\Theta$ when increased $\Psi$ no longer results in significant reductions in $\theta$ (Stephens and Rehfeldt, 1985). Using the modeled MCC data, easily available water, the water held between -10 and $-50 \mathrm{hPa}$, and water buffering capacity (WBC), the water held between -50 and $-100 \mathrm{hPa}$, were calculated for each of the seven substrates (de Boodt and Verdonck, 1972).

The MCC data based on effective saturation measured via the evaporative method were used along with the $K(\Psi)$ measurements to fit a $K(\Psi)$ model. This model predicted $K$ across the measured tension range and weighted the actual $K(\Psi)$ measurements to produce the strongest fit. The fit was computed (in HypropFit) with a nonlinear regression algorithm that minimized the sum of weighted squared residuals between model prediction (based on MCC measures) and measured $K$

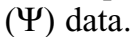

Greenhouse TriaL. On 5 May 2015, previously sealed drums were rolled horizontally on the ground to ensure homogenization and uniform moisture distribution for each of the seven substrates, and $0.14 \mathrm{~m}^{3}$ of each substrate was amended with $5.60 \mathrm{~kg} \cdot \mathrm{m}^{-3}$ of $15 \mathrm{~N}-3.9 \mathrm{P}-9.9 \mathrm{~K}$ controlledrelease fertilizer [3-month Osmocote Plus (micronutrients); Scotts Co., Marysville, $\mathrm{OH}]$ and $4.15 \mathrm{~kg} \cdot \mathrm{m}^{-3}$ lime $[1: 1$ crushed: pulverized (by weight)] by shovel turning the $0.14-\mathrm{m}^{3}$ piles three times, to ensure homogenization. Each substrate was used to fill 27 no. 1 (3.8 L) containers (C400; Nursery Supplies, Chambersburg, PA) loosely to the lip and packed by lifting and dropping from a $5-\mathrm{cm}$ height three times to provide a density comparable with the density of the cores packed in the laboratory portions of this research. Each filled container was planted with $H$. rosa-sinensis 'Fort Myers' plugs (Hatchett Creek Farms, Gainesville, FL). Each plant was placed in the center of the container and the container was dropped once from a height of $5 \mathrm{~cm}$ to complete planting. Five additional containers of each substrate were filled as previously described and left fallow. These fallow containers were immediately oven dried to determine substrate dry weight and Db. The 189 planted containers (seven substrates $\times 27$ containers) were moved into a shaded mist house, overhead irrigated by hand, and left in the mist house for $48 \mathrm{~h}$.

On 8 May 2015, all planted containers were randomly placed on one of three benches in a climate-controlled glass greenhouse. Each bench was separated into seven irrigation zones, with each zone consisting of a solenoid valve controlling 10 individual pressure-compensating spray stakes [plum color, 12.1 $\mathrm{L} \cdot \mathrm{h}^{-1}$ (Netafim USA, Fresno, CA)] used to water nine planted containers and a 1-L water collection vessel to measure irrigation volume. In addition, a lysimeter was randomly placed in each irrigation zone. Lysimeters were built by attaching 
$853.2-\mathrm{cm}^{2}$ square acrylic plates on either side of a load cell (LSP-10; Transducer Techniques, Temecula, CA). Plants were watered overhead as needed to establish roots within the container. During establishment, $150 \mathrm{~mL}$ liquid fertilizer solution made of $12 \mathrm{~g} \cdot \mathrm{L}^{-1}$ of soluble $20 \mathrm{~N}-13.2 \mathrm{P}-16.6 \mathrm{~K}$ (JR Peters, Allentown, PA) was applied to each container on 18 May, 28 May, and 15 June 2015.

On 29 June 2015, plants were fertilized with $150 \mathrm{~mL}$ of liquid fertilizer solution (prepared the same as previous solutions), and automated irrigation was initiated. Before this point, all plants were irrigated equally and the water volume applied was not incorporated in to water application calculations. This is considered the production portion of the experiment, at which time plant growth index [GI; (height + widest width + perpendicular width)/3] of each plant was measured about every $14 \mathrm{~d}$ until harvest. Lysimeters connected to a data logger (CR3000 Micrologger; Campbell Scientific, Logan, UT) via a multiplexer (AM16/32B Multiplexer; Campbell Scientific) were used to record the weight of one container per replication every $5 \mathrm{~min}$ and to actuate solenoids, turning on 10 spray stakes (one replication), via two relays (SDM-CD16AC; Campbell Scientific). Water was applied to a replication (nine containers and one collection vessel) when the minimum weight of the container was equal to a weight corresponding to $\theta$ with $\Psi$ of $-100 \mathrm{hPa}$ and irrigated until substrate reached a calculated weight corresponding to $\theta$ with $\Psi$ of $-50 \mathrm{hPa}$. Water potential was determined using the calculated substrate dry weight from the fallow containers to calculate $\theta$, and the MCCs were used to convert $\theta$ to $\Psi$. Because $\Psi$ discussed in this study were not directly measured but instead calculated through total water in substrate, they represent $\Psi$ corresponding to the average $\theta$ of the entire container.

The critical $\Psi$ range used corresponds with substrate WBC first described by de Boodt and Verdonck (1972), in which plant water is considered to be readily available (Pustjarvi and Robertson, 1975). Each zone was prevented from starting irrigation more than once every $3 \mathrm{~h}$ to prevent excess watering. In addition, air temperature $\left( \pm \mathrm{SD} ; 28.8 \pm 0.1{ }^{\circ} \mathrm{C}\right)$ and relative humidity $(65.4 \% \pm 0.6 \%)$ at canopy height were measured and recorded every 5 min with a sensor (HMP60; Vaisala, Vantaa, Finland) via the data logger, and used to calculate vapor pressure deficit (VPD). The water lost from the containers via evapotranspiration (ET) was calculated from lysimeter data every $5 \mathrm{~min}$ throughout the duration of the study and compiled and averaged hourly, as was VPD.

Water volume applied via the spray stake was measured periodically for each irrigation zone, which was used to confirm water application values measured via lysimeters. Integrated pest management procedures were used in the greenhouse during the experiment, which included applications of insecticide on 1 July 2015 (Safari; Valent BioSciences Corp., Libertyville, IL) and miticide on 31 July 2015 (Judo; OHP, Mainland, PA) to prevent pest damage.

INSTANTANEOUS WATER RELATIONS MEASUREMENTS. On 19 July 2015, a portable photosynthesis system (LI-6400XT; LICOR Biosciences, Lincoln, NE) with a light-emitting diode gas exchange chamber was used to measure leaf gas flux including net photosynthesis, stomatal conductance $\left(g_{\mathrm{s}}\right)$, and transpiration. Data were measured between 1045 and 1245 HR with the atmospheric and environmental parameters as follows $( \pm \mathrm{SD})$ : air temperature $=33.4 \pm 1.6{ }^{\circ} \mathrm{C}$; relative humidity $=40 \% \pm 5 \%$; photosynthetically active radiation $(P A R)=1300 \pm 0.8 \mu \mathrm{mol} \cdot \mathrm{m}^{-2} \cdot \mathrm{s}^{-1}$.
One randomly selected plant in each replication $(n=3)$ was used for instantaneous gas exchange measurements. The leaf chamber was clamped onto an apical mature leaf ensuring that the leaf was not contorted nor was the midrib in the clamped chamber, with the entire area of the chamber $\left(6 \mathrm{~cm}^{2}\right)$ covered with leaf tissue. This process was carried out quickly to minimize any possible shading that may affect the system or the plant. The chamber was set to mimic the $P A R$ of the sunlight, air temperature, and relative humidity of the greenhouse environment at the initiation of measurements. The $\mathrm{CO}_{2}$ concentration within the chamber was kept at $( \pm \mathrm{SE}) 400.2$ $\mu \mathrm{mol} \cdot \mathrm{mol}^{-1} \pm 0.1$. Containers were weighed before measuring gas exchange to ensure each was within the -50 to $-100 \mathrm{hPa}$ substrate $\Psi$ range. Instantaneous water use efficiency (WUE) of the treatments was calculated as net photosynthesis/transpiration.

Crop harvest. On 6 Aug. 2015 the final data collection and plant harvest was started. The irrigation control plant (on the lysimeter) in each zone had its leaves removed, leaf area (LA) measured (LI-3100C Area Meter; LI-COR Biosciences), and total leaf number counted. Leaf length, which is influenced by cell elongation (Pallardy, 2008), of the three most apical mature leaves, was measured from base to tip (excluding petiole) as an indicator of water stress throughout the experiment. Growth index was measured one last time on every plant in trial, and the difference between the GI at experiment initiation and harvest was calculated $(\Delta \mathrm{GI})$. Shoots were severed at the surface of the substrate and roots were washed free of substrate. All plant tissue was dried in a convection oven at $58{ }^{\circ} \mathrm{C}$ for $7 \mathrm{~d}$ before being weighed. An additional two plants per replication were harvested as described previously. The five most apical leaves on the two plants were separated and dried (dry weights were later added back to total shoot dry weight), so as to have 10 leaves from each zone. Five leaves from each zone were sent to the University of Georgia Stable Isotope Ecology Laboratory (Athens, GA) for $13 \mathrm{C}$ isotope discrimination $(\delta 13 \mathrm{C}$ ) analyses. Carbon-13 discrimination was used as an estimator of integrated WUE as it is an indicator of $g_{\mathrm{s}}$ over the duration of crop growth (Farquhar et al., 1989). The remaining five leaves sent to an analytical laboratory (T002 plant tissue analysis; Brookside Laboratories, New Bremen, $\mathrm{OH}$ ) to test for any differences in foliar nutrition during the study, with no differences in $\mathrm{N}(P=0.265)$ and $K(P=0.076)$ and a treatment effect on foliar $\mathrm{P}(P=0.031)$. Root to shoot ratio of dry weight $(\mathrm{R}: \mathrm{S})$ was then measured and used as an estimator of carbon allocation (Chartzoulakis et al., 1993). Plant compactness was calculated as the ratio of shoot dry weight to shoot height, so that larger values represent more compact plants (van Iersel and Nemali, 2004). Integrated WUE was also calculated by dividing total plant dry biomass by ET. The hourly ET measures were plotted against hourly calculated VPD, with nighttime values removed when insignificant amounts of water were loss through ET. This was carried out to provide insight into the ability of the substrate to allow water movement when environmental (both rooting and atmospheric environment) demand increased.

Plant water avallability. On 11 Aug. 2015, the three remaining plants in each replication had the spray stakes removed. One randomly selected remaining plant in each replication was placed on the respective lysimeter. Container system weight (plant + container + substrate) was recorded every $5 \mathrm{~min}$ to calculate water status. Air temperature $( \pm \mathrm{SD})$ $\left(27.3 \pm 0.3{ }^{\circ} \mathrm{C}\right)$ and relative humidity $(63.4 \% \pm 1.1 \%)$ was 
measured every 5 min throughout the dry down to determine VPD. Plants were irrigated overhead by hand until each reached effective $\mathrm{CC}$ [the maximum water holding capacity possible through overhead irrigation $\left.\left(\mathrm{CC}_{\mathrm{E}}\right)\right]$, based on container system weight. Water was then withheld from each plant for $\approx 2$ weeks, at which time every plant was completely wilted and water loss was negligible for $>2 \mathrm{~d}$. As plants dried down, the lysimeter measured water loss. The reduction in $\theta$ over each $24 \mathrm{~h}$ period (from 0000 to $0000 \mathrm{HR}$ ) were plotted against the starting $\theta$ for that period. Data were regressed to calculated the critical point where the daily water use shifted to "stable" reductions in $\theta$. This allows inferences into the $\theta$ where water loss shifts from ET (large reductions in $\theta$ ), to primarily evaporation (constantly low reductions in $\theta$ ), in an effort to estimate at what $\theta$ each plant stopped transpiring. The water remaining in the substrate when plants ceased transpiring was considered to be the unavailable (O’Meara et al., 2014).

Statistical analyses. Data presented in tables with associated statistics were analyzed in JMP Pro (12.0.1; SAS Institute) using Tukey's honestly significant difference $(\alpha=$ 0.05 ) to separate means across all seven substrates. Substrates PF6, PF4, PF2, and PF0 were further analyzed to detect any potential linear or quadratic relationships that may exist between measurements and substrate mean particle diameter $(\mathrm{PF} 6=4.66 \mathrm{~mm}, \mathrm{PF} 4=2.58 \mathrm{~mm}, \mathrm{PF} 2=2.07 \mathrm{~mm}$, and PF0 = $0.69 \mathrm{~mm}$ based on dry weight) to understand the effect of particle size fractionation. A $t$ test was used to specifically compare peat and coir, to determine how the two fibers influence substrates differently. The data in tables without accompanying statistics are computed from fitted Brooks and Corey (1964) models. Correlation data, when used, were calculated using Pearson product-moment correlation coefficient in JMP Pro (12.0.1) using raw data.

\section{Results and Discussion}

Hydrophysical properties. There was no detectable difference in texture or $\mathrm{Db}$ between the fiber-amended substrates, P35 and C40 (Table 1). The quantity of small and medium texture particles in the P35 and C40 substrates was much lower than in the UPB [by dry weight (Table 1)]; however, the fibrous additions resulted in a similar (C40) or 5.3\% (by volume) greater (P35) CC (Table 2). Peat and coir amendments were almost completely composed of particles in the small texture class when measured individually (data not presented) resulting in the $\mathrm{C} 40$ having greater $\mathrm{AS}(4.6 \%$ by volume; $P=0.045)$ and lower CC $(3.0 \%$ by volume; $P=0.089)$, when compared with P35. The UPB had an AS [32.32\% (by volume)] between PF0 and $\mathrm{PF} 2$, and a $\mathrm{CC}[48.2 \%$ (by volume)] representing the median of all seven substrates (Table 2). Substrate water storage and delivery is influenced by the differing particle geometries of the individual components, corresponding to the ability of the fibrous materials to increase the degree of pore connectivity, beyond that of the plate-like particles occurring in the unprocessed (UPB) and fractionated bark only substrate which remain large and unconnected. Thus, the addition of the fibrous materials resulted in the substrates being able to hold more water than UPB in the $3.8-\mathrm{L}$ container because of resulting pore structure and increased surface area, although coir- and peat-amended substrates were engineered to have physical properties $\mathrm{CC}, \mathrm{AS}$, and TP closely resembling that of the UPB (Table 2) using the porometer.
Table 1. Particle size distribution (percent on dry weight basis) grouped into three texture classes (large, medium, and small) and bulk density $(\mathrm{Db})$ for seven experimental pine bark based substrates.

\begin{tabular}{lcccc}
\hline $\begin{array}{l}\text { Substrate } \\
\text { zentrol }\end{array}$ & $\begin{array}{c}\text { Large } \\
(>2 \mathrm{~mm})\end{array}$ & $\begin{array}{c}\text { Medium } \\
(2.0-0.7 \mathrm{~mm})\end{array}$ & $\begin{array}{c}\text { Small } \\
(<0.7 \mathrm{~mm})\end{array}$ & $\begin{array}{c}\mathrm{Db} \\
\left(\mathrm{g} \cdot \mathrm{cm}^{-3}\right)\end{array}$ \\
\hline $\begin{array}{l}\text { UPB } \\
\text { Conticle size }\end{array}$ & $\begin{array}{c}50.8 \mathrm{e}^{\mathrm{y}} \\
\text { fractionation }\end{array}$ & $32.3 \mathrm{~b}$ & $16.0 \mathrm{~b}$ & $0.18 \mathrm{~b}$ \\
Particl & & & \\
PF0 & $1.1 \mathrm{f}$ & $59.4 \mathrm{a}$ & $39.5 \mathrm{a}$ & $0.32 \mathrm{a}$ \\
PF2 & $61.6 \mathrm{~d}$ & $33.3 \mathrm{~b}$ & $5.1 \mathrm{~cd}$ & $0.19 \mathrm{bc}$ \\
PF4 & $82.9 \mathrm{~b}$ & $12.6 \mathrm{~d}$ & $4.5 \mathrm{~d}$ & $0.15 \mathrm{~cd}$ \\
PF6 & $92.5 \mathrm{a}$ & $4.5 \mathrm{e}$ & $3.0 \mathrm{~d}$ & $0.15 \mathrm{bcd}$ \\
Linear & 0.0002 & $<0.0001$ & 0.0038 & 0.0056 \\
Quadratic & $<0.0001$ & $<0.0001$ & $<0.0001$ & $<0.0001$ \\
Fiber additions & $68.2 \mathrm{~cd}$ & $25.3 \mathrm{c}$ & $6.5 \mathrm{~cd}$ & $0.14 \mathrm{~cd}$ \\
P35 & $69.7 \mathrm{c}$ & $21.7 \mathrm{c}$ & $8.6 \mathrm{c}$ & $0.13 \mathrm{~d}$ \\
C40 & 0.3322 & 0.9249 & 0.1049 & 0.1012 \\
$P^{\mathrm{w}}$ & &
\end{tabular}

$\overline{{ }^{\mathrm{z}} \text { Stabilized, unprocessed pine bark (UPB) }<12.7 \mathrm{~mm} \text {; bark screened }}$ while at $65 \%$ moisture content $<2.3-\mathrm{mm}$ screen (PF0), $2.3-4.0 \mathrm{~mm}$ (PF2), 4.0-6.3 mm (PF4), >6.3-mm screen (PF6); and PF4 amended (by volume) amended with fibrous materials including $35 \%$ sphagnum peat (P35) and 40\% coconut coir (C40).

${ }^{\mathrm{y}}$ Means within a column followed by the same letter are not significantly different (Tukey's honestly significant difference at $\alpha=$ $0.05)$.

${ }^{\mathrm{x}}$ Probability values for linear and quadratic relationships between mean particle diameter and response variable within particle fractionation $(\mathrm{PF})$ substrates.

${ }^{\text {w}}$ Probability value comparing differences between P35 and C40 substrates $(t$ test $)$.

Mean particle diameter of each processed substrate exhibited a strong quadratic relationship with all three texture classes $\left[R^{2}=\right.$ $0.996,0.959$, and 0.984 for large, medium, and small, respectively (Table 1)] as anticipated. Mean particle diameter decreased with each decreasing texture class. A strong quadratic relationship based on mean particle diameter $\left(R^{2}=0.984,0.996\right.$, 0.996, for CC, AS, and TP, respectively) was observed across static physical properties for substrates (PF0, PF2, PF4, and PF6) that underwent particle fractionation (Table 2). Decreasing particle diameter resulted in increased $\mathrm{CC}$ with PF0 having the greatest CC of [ $58.5 \%$ (by volume)] which was nearly two times that of the other three particle fractions (PF2, PF4, and PF6), similar to the observations made by Richards et al. (1986), where the removal of pine bark particles $>2 \mathrm{~mm}$ increased water holding capacity in a bark substrate. Conversely, increased particle diameter increased AS. The PF6 and PF4 substrate had the largest AS, whereas the PF2 had lower AS than PF6. The PF0 has about less than one-third the AS compared with the PF6, PF4, and PF2. These relationships of the air- and water-holding characteristics of the particle size fractionated substrates coincides with similar relationships between mineral soils based on their relative particle size due to the inherent differences in surface area and the pore size distribution (Jury and Horton, 2004). The PF0 substrate was the only substrate with the recommended properties as reported in the Southern Nursery Association's Best Management Practices manual (Bilderback et al., 2013), with the PF6, PF4, and PF2 substrates having greater AS and lower CC than recommended, and the UPB, P35, and $\mathrm{C} 40$ having slightly greater AS than recommended. 
Table 2. Hydrophysical properties for seven pine bark-based substrates including, unprocessed bark (UBP), four screened barks, and substrates comprised $6.3 \mathrm{~mm}$ bark amended with 35\% (by volume) sphagnum peat (P35) or $40 \%$ (by volume) coconut coir (C40). Easily available water (EAW), water buffering capacity (WBC) and permanent wilt point are computed from data fit to a Brooks and Corey (1964) model, and therefore have no associated statistics outside of their respective models.

\begin{tabular}{|c|c|c|c|c|c|c|c|c|}
\hline Substrate $^{z}$ & $\begin{array}{c}\mathrm{CC}^{\mathrm{y}} \\
\left(\mathrm{m}^{3} \cdot \mathrm{m}^{-3}\right)\end{array}$ & $\begin{array}{l}\text { Air space } \\
\left(\mathrm{m}^{3} \cdot \mathrm{m}^{-3}\right)\end{array}$ & $\begin{array}{c}\mathrm{TP}^{\mathrm{w}} \\
\left(\mathrm{m}^{3} \cdot \mathrm{m}^{-3}\right)\end{array}$ & $\begin{array}{c}\mathrm{EAW}^{\mathrm{v}} \\
\left(\mathrm{m}^{3} \cdot \mathrm{m}^{-3}\right)\end{array}$ & $\begin{array}{c}\mathrm{WBC}^{\mathrm{u}} \\
\left(\mathrm{m}^{3} \cdot \mathrm{m}^{-3}\right)\end{array}$ & $\begin{array}{c}\text { Total container } \\
\text { water load }\left(\mathrm{cm}^{3}\right)\end{array}$ & $\begin{array}{c}\text { Saturated hydraulic } \\
\text { conductivity } \\
\left(\log _{10} \mathrm{~cm} \cdot \mathrm{d}^{-1}\right) \\
\end{array}$ & $\begin{array}{c}\theta \text { at }-1.5 \\
\mathrm{MPa}^{\mathrm{r}} \\
\left(\mathrm{m}^{3} \cdot \mathrm{m}^{-3}\right)\end{array}$ \\
\hline \multicolumn{9}{|l|}{ Control } \\
\hline \multicolumn{9}{|c|}{ Particle fractionation $(\mathrm{PF})$} \\
\hline PF0 & $0.585 \mathrm{a}$ & $0.148 \mathrm{e}$ & $0.732 \mathrm{~d}$ & 0.26 & 0.03 & $232.2 \mathrm{a}$ & $3.79 \mathrm{c}$ & 0.137 \\
\hline PF2 & $0.331 \mathrm{~d}$ & $0.443 \mathrm{~b}$ & $0.791 \mathrm{c}$ & 0.09 & 0.02 & $132.1 \mathrm{c}$ & $4.76 \mathrm{a}$ & 0.109 \\
\hline PF6 & $0.271 \mathrm{e}$ & $0.525 \mathrm{a}$ & $0.796 \mathrm{c}$ & 0.05 & 0.02 & $72.4 \mathrm{~d}$ & $4.72 \mathrm{a}$ & 0.100 \\
\hline Linear $^{p}$ & 0.007 & 0.001 & 0.0149 & NA & NA & 0.0001 & 0.1271 & NA \\
\hline Quadratic $^{\circ}$ & $<0.0001$ & $<0.0001$ & 0.0007 & NA & NA & $<0.0001$ & 0.0878 & NA \\
\hline \multicolumn{9}{|c|}{ Fiber additions ${ }^{\mathrm{n}}$} \\
\hline P35 & $0.534 \mathrm{~b}$ & $0.309 \mathrm{~d}$ & $0.843 \mathrm{ab}$ & 16.6 & 6.3 & $238.3 \mathrm{a}$ & $3.58 \mathrm{c}$ & 0.113 \\
\hline $\mathrm{C} 40$ & $0.504 \mathrm{bc}$ & $0.355 \mathrm{c}$ & $0.859 \mathrm{a}$ & 14.4 & 3.4 & $197.0 \mathrm{~b}$ & $3.72 \mathrm{c}$ & 0.148 \\
\hline
\end{tabular}

${ }^{\mathrm{z}}$ Stabilized, unprocessed pine bark (UPB) $<12.7 \mathrm{~mm}$; bark screened while at $65 \%$ moisture content $<2.3-\mathrm{mm}$ screen (PF0), 2.3-4.0 mm (PF2), 4.0-6.3 mm (PF4), >6.3-mm screen (PF6); and PF4 amended (by volume) amended with fibrous materials including $35 \%$ sphagnum peat (P35) and $40 \%$ coconut coir $(\mathrm{C} 40)$.

${ }^{\mathrm{y}}$ Container capacity (CC) is the maximum percentage of substrate volume occupied by water after allowing to drain for $1 \mathrm{~h}$.

${ }^{\mathrm{x}}$ Air space is the minimum percentage of substrate volume occupied by air after allowing to drain for $1 \mathrm{~h}$.

${ }^{\mathrm{w}}$ Total porosity (TP) is the percentage of substrate volume not occupied by solid particles; often calculated as TP $=\mathrm{CC}+\mathrm{AS}$.

${ }^{\mathrm{v}}$ Percentage of substrate volume occupied by water that is released between -10 and $-50 \mathrm{hPa}$ of tension.

${ }^{u}$ Percentage of substrate volume occupied by water that is released between -50 and $-100 \mathrm{hPa}$ of tension.

${ }^{t}$ Volume of water kept between -50 and $-100 \mathrm{hPa}$ of tension for a 3.8-L container. Calculated based on moisture characteristic curves and individual container substrate volumes.

${ }^{\mathrm{s}}$ A quantitative measure of the ability for the substrate to transmit water when subjected to a hydraulic gradient.

${ }^{\mathrm{r}}$ Volumetric water content of a substrate when substrate water potential is $-1.5 \mathrm{MPa}$.

${ }^{\mathrm{q}}$ Means separated across all seven substrates (entire column) using Tukey's honestly significant difference, $\alpha=0.05$.

${ }^{\mathrm{p}}$ Probability of linear relationship among PF substrates based on mean particle diameter.

${ }^{\circ}$ Probability of quadratic relationship among PF substrates based on mean particle diameter.

${ }^{\mathrm{n}}$ Substrate engineering process involving amending pine bark particles that do not pass through a 6.3 -mm screen while at $65 \%$ moisture content with fibrous materials to match static physical properties of UBP.

There was no detectable difference in $K_{\mathrm{s}}$ between the two substrates with fibrous particles added, nor was any relationship observed between $K_{\mathrm{s}}$ and mean particle diameter (Table 2). The $K_{\mathrm{s}}$ values for the PF6, PF4, and PF2 were greater than that of the PF0, UPB, or fiber-amended substrates. This relationship between $K_{\mathrm{s}}$ and mean particle diameter is similar to results shown by Heiskanen (1999) in peat-based substrates, who noted that the presence of larger particles increase $K_{\mathrm{s}}$. Large particles can increase the proportion of TP occupied by macropores. The PF2, PF4, and PF6, engineered with intent to reduce the phenomena of hysteresis by creating more uniform pore sizes, have inherently reduced tortuosity when hydrated, and allow an increased rate of water flow at optimal container growing $\Psi$ (substrate water potentials between -50 and $-100 \mathrm{hPa}$ ). With the inclusion of greater proportions of finesized particles in a substrate, smaller diameter pores are formed, which restrict water movement more than larger diameter pores, resulting in increased substrate tortuosity when hydrated, thus, increasing physical retardation of water as it passes through the substrate. However, as $\theta$ is decreased, the water must move along particle surfaces, resulting in increased substrate tortuosity (Fonteno, 1993). Therefore, we hypothesize that tortuosity increased more in the coarse materials than the fine materials as substrates dry.
Dewpoint hygrometry resulted in increased (less negative) $\Psi$ at low $\Theta$ for substrates with fibrous additions compared with substrates measured with tensiometers and the evaporative method [C40 and P35 (Fig. 1F and G)]. This is hypothesized to be a result of the small sample size used in analysis. Using a coarse bark in dewpoint hygrometry and small substrate volumes $\left(\approx 5 \mathrm{~cm}^{3}\right)$ results in samples that may not structurally mimic the composite substrate in the $250-\mathrm{cm}^{3}$ cores or in the container where the volume would be dominated by large bark particles, further influencing the $\theta$ at each tension. Another possible explanation for the discrepancy between dewpoint hygrometry and low tension evaporative measures is degrading hydraulic connectivity between substrate particles and the tensiometers as the sample dries. Evaporation from the sample is a transient process, which does not allow the sample to reach equilibrium at each measure, and thus, poor contact may establish during measurements.

Moisture characteristic curves for each substrate were fit to a model [Brooks and Corey, 1964 (Fig. 1)], which provided $\lambda$, $H_{\mathrm{b}}, \Theta_{s}$, and $\Theta_{r}$. Pore uniformity increased in all experimental substrates except the PF6 substrate, which comprised primarily coarse particles, when compared with UPB. The PF6 substrate exhibited the lowest $\lambda(0.19$; Table 3$)$ representing the least uniform pore size distribution. The UPB, P35, PF2, PF4, and 

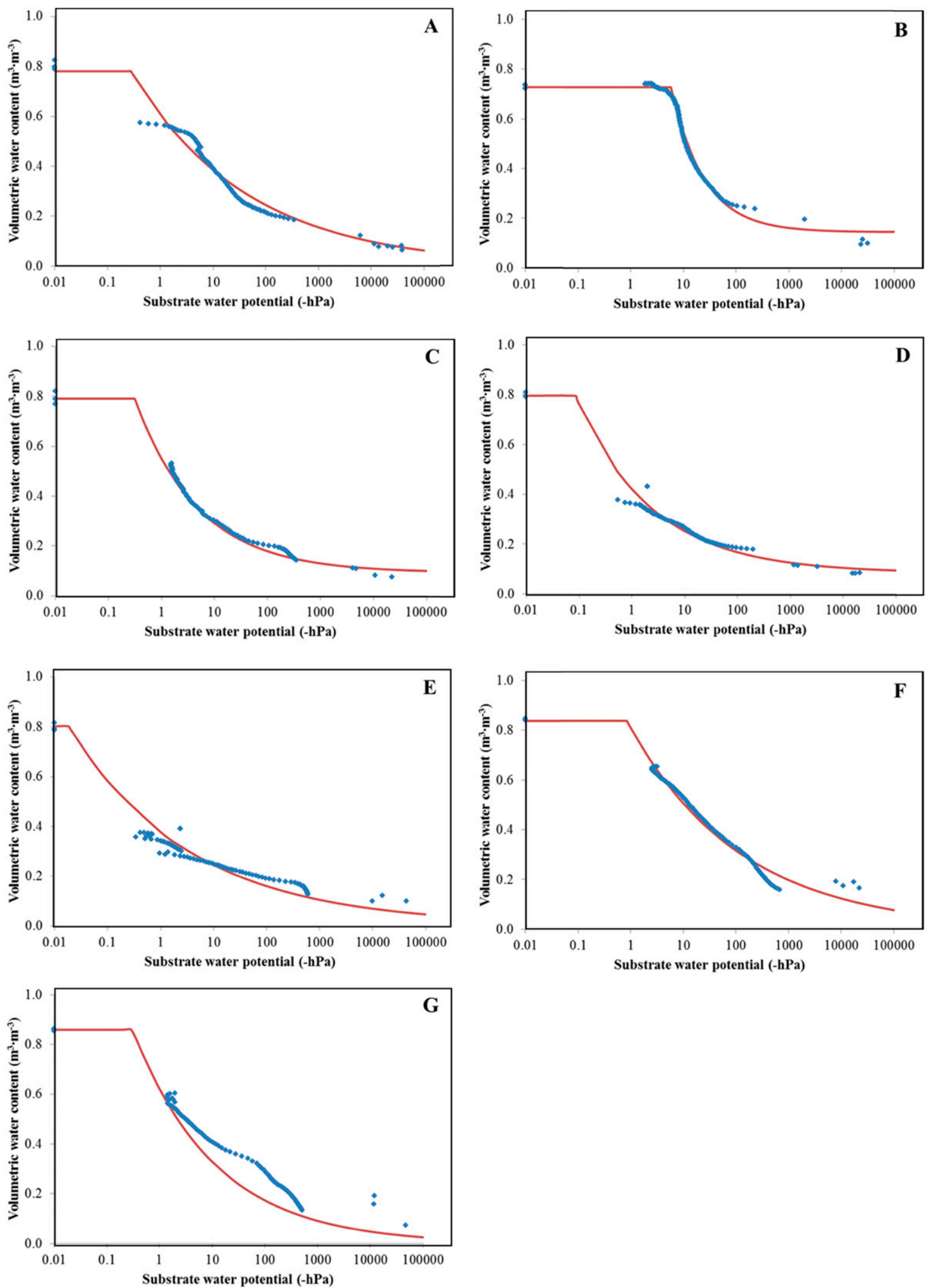

Fig. 1. Measured moisture characteristic curve data (points) fit to Brooks and Corey (1964) models (line) for seven substrates including unprocessed pine bark [UPB (A)]; bark screened while at 65\% moisture content $<2.3 \mathrm{~mm}$ [PF0 (B)], 2.3-4.0 mm [PF2 (C)], 4.0-6.3 mm [PF4 (D)], and >6.3-mm screen [PF6 (E)]; and PF4 amended (by volume) amended with fibrous materials including 35\% sphagnum peat [P35 (F)] and 40\% coconut coir [C40 (G)]. Data measured using porometer, evaporative analysis, and dewpoint potentiametry for saturation, -1 to $-1000 \mathrm{hPa}$, and $<-1000 \mathrm{hPa}$, respectively. Model fit parameters are presented in Table 3 . 
Table 3. Fit model parameters for the relationship between volumetric water content $(\theta)$ and substrate water potential for seven experimental pine bark-based substrates. Data were fit to a Brooks and Corey (1964) porous media moisture tension model with parameters provided within this table, and therefore have no associated statistics.

\begin{tabular}{lclcccc}
\hline Substrate $^{\mathrm{z}}$ & $\Theta_{s}{ }^{\mathrm{y}}\left(\mathrm{m}^{3} \cdot \mathrm{m}^{-3}\right)$ & $\Theta_{r}{ }^{\mathrm{x}}\left(\mathrm{m}^{3} \cdot \mathrm{m}^{-3}\right)$ & $H_{\mathrm{b}}{ }^{\mathrm{w}}(\mathrm{hPa})$ & $\lambda^{\mathrm{v}}$ & $R^{2}$ & $\mathrm{RMSE}^{\mathrm{u}}\left(\mathrm{m}^{3} \cdot \mathrm{m}^{-3}\right)$ \\
\hline UPB & 0.781 & $0.034 \times 10^{-7}$ & 0.277 & 0.1968 & 0.95 & 4.32 \\
PF0 & 0.727 & 0.146 & 5.788 & 0.6896 & 0.99 & 1.68 \\
PF2 & 0.791 & 0.093 & 0.312 & 0.3628 & 0.99 & 1.35 \\
PF4 & 0.796 & 0.084 & 0.085 & 0.3036 & 0.88 & 2.83 \\
PF6 & 0.802 & 0.006 & 0.018 & 0.1905 & 0.96 & 5.37 \\
P35 & 0.837 & $0.034 \times 10^{-7}$ & 0.848 & 0.2041 & 0.98 & 2.67 \\
C40 & 0.859 & 0.105 & 0.288 & 0.2682 & 0.96 & 3.30
\end{tabular}

${ }^{\bar{z}}$ Substrates include unprocessed pine bark (UPB), substrates engineered through sieving pine bark while at $65 \%$ moisture content through a series of screens. Particles that pass through a $2.3-\mathrm{mm}$ screen (PF0), a 4.0-mm screen but not a 2.3-mm screen (PF2), 6.3-mm screen but not a 4.0-mm screen (PF4), and pine bark particles that do not pass through a $6.3-\mathrm{mm}$ screen (PF6) while at $65 \%$ moisture content, and Substrate engineering process involving amending pine bark particles that do not pass through a $6.3-\mathrm{mm}$ screen while at $65 \%$ moisture content with fibrous materials to match static physical properties of unprocessed bark using $35 \%$ sphagnum peat (P35) and $40 \%$ coconut coir (C40) by volume.

${ }^{\mathrm{y}}$ Volumetric water content at saturation.

${ }^{\mathrm{x}}$ Volumetric water content at a tension where further increasing moisture tension does not further reduce volumetric water content.

${ }^{\mathrm{w}}$ Bubbling pressure (tension which air first enters the substrate).

${ }^{\mathrm{v}}$ Pore size distribution uniformity index, larger values represent increased pore uniformity.

${ }^{\mathrm{u}}$ Root mean square error (RMSE) of the predictive model compared with the observed data.

C40 had larger $\lambda$ values, with PF0 exhibiting the maximum observed pore size uniformity $(0.69)$. The intent of the particle fractionation was to create a range of pore uniformity, to understand subsequent effects on substrate water dynamics. The Brooks and Corey model predicted the lowest air entry pressures for the PF4 and PF6 substrates. The model fit extremely small bubbling pressures for PF4 and PF6 [0.085 and $0.018 \mathrm{hPa}$, respectively (Table 3)], indicating the inability of these substrates to retain water in pores even against miniscule tensions. Furthermore, this would suggest that the perched water table in these two substrates (PF4 and PF6) would likely be unmeasurable. The air entry pressure is generally indicative of the largest diameter, nonhysteretically restricted pore when assuming the capillary bundle theory. However, this theory may not be indicative of the true nature of the porous substrate, as many measured pores can be virtual (measured porosity that does not exist), due to hysteretic effects influencing at what tension water is released from pores (Hunt et al., 2013). This, along with impractically large measures of $K_{\mathrm{s}}$ and high proportion of macropore volume that increased drainage resulting in lower water holding capacity (Argo, 1998), is why these substrates are considered to be water inefficient under conventional cultural practices (i.e., regular irrigation).

The difference in $\theta$ between CC and $\Psi_{100}$ in P35 and C40 implies that coir improves the rate of drainage and aeration at conventional production hydration levels compared with sphagnum peat. This difference in aeration between $\mathrm{C} 40$ and P35 was also observed with AS (Table 2). However, $\Theta_{r}$ values from modeled MCCs showed that the $\Theta$ of $C 40\left(0.11 \mathrm{~m}^{3} \cdot \mathrm{m}^{-3}\right)$ was greater at low $\Psi$ when compared with P35 which approached $0\left[3.3 \times 10^{-7} \mathrm{~m}^{3} \cdot \mathrm{m}^{-3}\right.$ (Table 3) $]$. This indicates that although coir increased aeration within conventional production ranges to a greater degree than peat, when extreme dry situations occur, coir retained more water that is available for plant use and may help prevent crop death if water is purposely or accidently withheld. A similar observation was made by Fields et al. (2014b), where a $100 \%$ coir substrate exhibited greater $\theta$ compared with a $100 \%$ peat substrate at $-300 \mathrm{hPa}$ and $-1.5 \mathrm{MPa}$. Furthermore, coir has been shown to remain hydrophilic, unlike peat which becomes hydrophobic, when allowed to dry (Fields et al., 2014a). This phenomenon of coir to remain hydrophilic and retain increased water in dry situations contributes to the increased water availability in coir substrates at low $\Psi$.

The $K(\Psi)$ data measured via the evaporative method were plotted between 0 and $-300 \mathrm{hPa}$ (Fig. 2A), fit to a model that used MCC model parameters and $K(\Psi)$ measures, and plotted for $\Psi$ between -50 and -100 $\mathrm{hPa}$, corresponding to the $\mathrm{WBC}$ range (Fig. 2B). The RMSE for the models to all the data points were low, indicating good fits. The P35 had $K$ two orders of magnitude greater than the other experimental substrates across $\mathrm{WBC}$ range. This indicates that the addition of peat to a coarse substrate can greatly increase $K$ at $\Psi$ between -50 and $-100 \mathrm{hPa}$. The $K$ of the $\mathrm{C} 40$ was less than the P35, although being similar to P35 in most other hydrophysical properties. With both $\mathrm{P} 35$ and $\mathrm{C} 40$ similar in $K_{\mathrm{s}}, \mathrm{CC}$, and TP, the reduced $K$ between $\Psi_{-50}$ and $\Psi_{-100}$ suggests that coir, as a substrate component, conducted water to a lesser degree than peat. The curves for the four particle fractionation substrates follow a similar trend (Fig. 2); however, the $K$ of PF4 was lower across the range than PF6. It is hypothesized that the sieving process caused the PF4 fraction to have more uniform medium texture particles and less small texture particles from the double screening process than the PF6 bark. Although this phenomenon also occurs in the PF2 fraction, the particles are smaller than in the PF6 and PF4, thus increasing $K$, while also increasing surface area, which allowed for an increase in the proportion of extremely fine sized particles $(<0.11 \mathrm{~mm}$ diameter) in the hydrated screening process (data not shown).

To further compare the $K(\Psi)$ curves, the values of $K$ at $-75 \mathrm{hPa}\left[K\left(\Psi_{75}\right)\right]$ for each substrate were calculated $[\mathrm{UPB}=-2.72$, $\mathrm{PF} 0=-2.60, \mathrm{PF} 2=-2.95, \mathrm{PF} 4=-3.20, \mathrm{PF} 6=-3.06, \mathrm{P} 35=$ $-0.74, \mathrm{C} 40=-2.80$; all $K$ values are $\left.\log _{10} K\left(\mathrm{~cm} \cdot \mathrm{d}^{-1}\right)\right]$ from the fit model. The UPB and C40 substrate were similar at $K\left(\Psi_{75}\right)$ to the PF0 and PF2 substrates. However, the mean slope of $\mathrm{UPB}$, was the most negative across the -50 to $-100 \mathrm{hPa}$ range $\left[-0.0181 \mathrm{~cm} \cdot \mathrm{d}^{-1} \cdot \mathrm{hPa}^{-1}\right.$ (Fig. 2)]. The $K$ for the UPB decreased to below that of the $\mathrm{C} 40$ at $\approx-88 \mathrm{hPa}$ over the -50 to $-100 \mathrm{hPa}$ range (Fig. 2B). The values of $K$ between -50 and $-100 \mathrm{hPa}$ are $\approx 10^{-3}$ lower than that of measured $K_{\mathrm{s}}$ values. This agrees with previous findings for peat-based soilless substrates that showed substrate $K$ decreases by three orders of magnitude over the 0 to $-25 \mathrm{hPa}$ substrate water potential range (da Silva et al., 1993; Wallach et al., 1992), and that $K$ for peat and bark sharply decline at -30 and $-50 \mathrm{hPa}$, respectively (Naasz et al., 2005). This indicates rapid decline in the ability of a substrate 


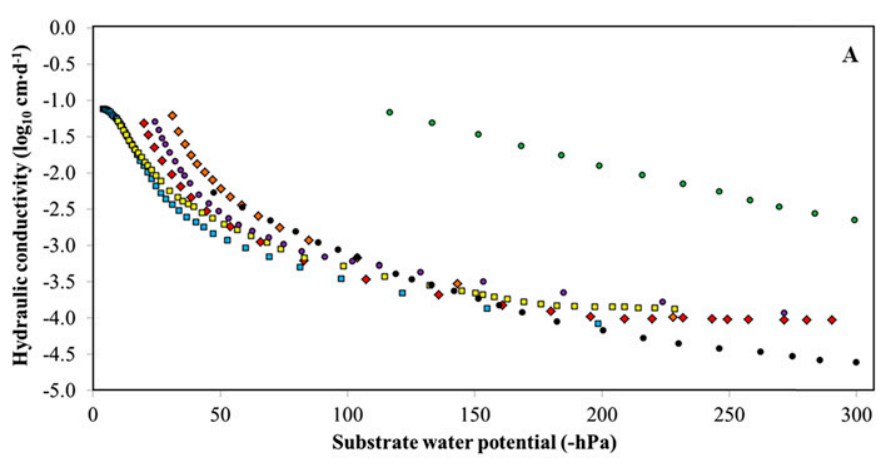

- $\mathrm{PF} 0 \cdot \mathrm{PF} 2$ - $\mathrm{PF} 4$-PF6 • UPB •P35 • C40

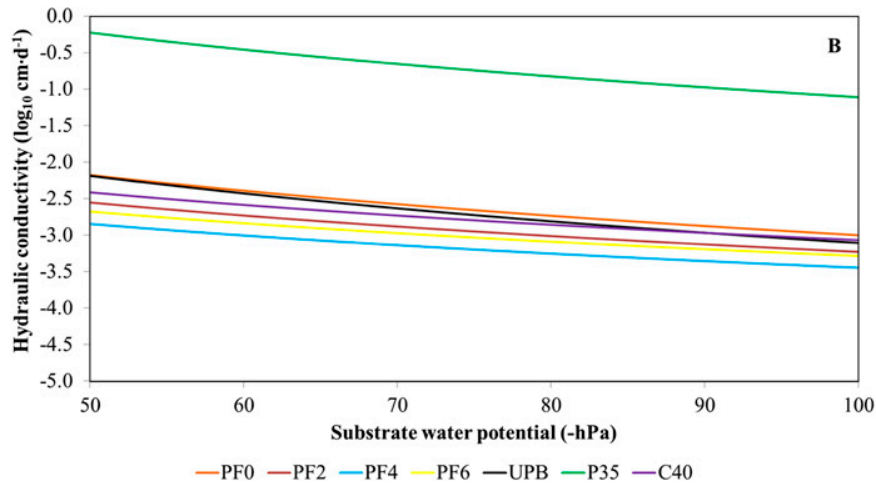

Fig. 2. Unsaturated hydraulic conductivity $(K)$ data plotted against substrate water potential $[K(\Psi)]$ for seven substrates including unprocessed pine bark (UPB); bark screened while at $65 \%$ moisture content $<2.3 \mathrm{~mm}$ (PF0), 2.3 $4.0 \mathrm{~mm}$ (PF2), 4.0-6.3 mm (PF4), >6.3-mm screen (PF6); and PF4 amended (by volume) amended with fibrous materials including $35 \%$ sphagnum peat (P35) and 40\% coconut coir (C40). Individual data points (A) measured via evaporative method via difference in tension between two depths in core as moisture evaporates, and (B) models representing $K$ data between substrate water potentials of -50 and $-100 \mathrm{hPa}$ (water-buffering capacity) attained from fitting moisture tensions measures to a Mualem (1976) model while weighting for actual data measures in $\mathbf{A}$. The root mean square error for the models to the data were $0.13,0.19,0.16,0.04,0.12,0.12$, and $0.18 \log _{10} \mathrm{~cm} \cdot \mathrm{d}^{-1}$ for the PF0, PF2, PF4, PF6, UPB, P35, and C40, respectively.

to conduct water, and therefore, reduced the water availability to the plant. In addition, Londra (2010) found perlite amended with coir to have higher unsaturated $K$ than perlite amended with peat at $40 \% \theta$, which would be at a higher (less negative) $\Psi$ than that used in our data. The $K_{\mathrm{s}}$ values for the C40 were larger than that of the P35. Therefore, we expect coir-amended substrate to have higher $K$ than peat-amended substrate as $\Psi$ approaches $0 \mathrm{hPa}$, and a more dramatic decrease in $K$ in coiramended substrates between saturation and $-50 \mathrm{hPa}$. However, substrate $K$ is less limiting for water movement as $\Psi$ approaches $0 \mathrm{hPa}$. Researchers will often measure $K_{\mathrm{s}}$ as opposed to unsaturated $K$, because of the relative ease of measurements (Caron and Elrick, 2005); however, measurements of $K_{\mathrm{s}}$, did not correlate strongly with $K\left(\Psi_{75}\right)$ values $(r=$ $0.32, P=0.156$ ), and thus, do not provide insight into production ranges. Consequently, the authors believe that measures of unsaturated $K$, especially within traditional production water potential ranges, should be used to provide information toward better understanding water-substrate interactions.

Plant responses and water status. Plants grown in PF0 and P35 had the greatest $\Delta \mathrm{GI}$ (Table 4). Although plants grown in the PF0 substrate had a greater $\Delta \mathrm{GI}$, crop $\Delta \mathrm{GI}$ in P35 was similar to that of plants in C40 and UPB. Although each of these substrates resulted in salable crops (author observations based on plant size and overall health), the greatest $\Delta$ GI came from plants grown in PF0, the only substrate to conform to all the southeastern United States best management practices for static physical properties (Bilderback et al., 2013). No difference in $\mathrm{R}: \mathrm{S}$ was observed among plants grown in the seven substrates $(P=0.844)$, suggesting that although some substrates were able to produce larger crops, water availability was sufficient to ensure none of the substrates caused shifts in carbon allocation between roots and shoots (i.e., variation in R:S). Moreover, leaf length revealed no differences among treatments $(P=0.940)$, providing further evidence that none of the substrates imposed serious water stress on the plants. The lack of stress indicators (e.g., LA, leaf length, compactness) is likely a result of all crops being grown at equivalent $\Psi$ ranges. Conversely, there were differences among the plants grown in different substrates in regards to canopy compactness and LA (Table 4). Leaf area of crops produced in the $\mathrm{P} 35$ and $\mathrm{C} 40$ substrates were greater than when produced in the PF6 substrate (Table 4). No differences were found for compactness with any of the engineered substrates when compared with UPB which had median compactness. Within the engineered substrates; more compact plants occurred in P35, C40, and PF0 substrates than when grown in PF4 and PF6 substrates. Increased compactness in Hibiscus acetosella has been linked to higher substrate moisture during production (Bayer et al., 2013). This indicates that plants grown in substrates with higher unsaturated $K$ are able to continuously access and withdraw water more readily than plants grown in substrates with lower unsaturated $K$. In addition, there was a strong quadratic relationship among mean particle size and both LA $\left(R^{2}=0.986\right)$ and compactness $\left(R^{2}=\right.$ 0.999) (Table 4). However, compactness had a quadratic relationship with $K\left(\Psi_{75}\right)$, suggesting that the $K$ influenced crop morphology $\left(R^{2}=0.710\right)$.

Change in GI $(r=-0.64 ; P=0.002)$, LA $(r=-0.65 ; P=$ $0.002)$, compactness $(r=-0.59 ; P=0.005)$, and R:S $(r=0.49$; $P=0.024)$ correlated with $\delta 13 \mathrm{C}$, suggesting that the substrate, which was shown to influence these morphological and physiological parameters, also influenced $\delta 13 \mathrm{C}$ of the leaf tissue. Tukey's honestly significant difference was unable to detect any difference in $\delta 13 \mathrm{C}$ among the plants grown in the seven substrates when separating means (Table 4); however, analysis of variance before means separation did suggest treatment effects across all seven substrates $(P=0.031)$. Egilla et al. (2005) observed a decrease in $\delta 13 \mathrm{C}$ in drought-stressed container-grown $H$. rosa-sinensis, and concluded that WUE increased with drought stress. Thus, from $\delta 13 \mathrm{C}$ measures, we conclude that the substrate treatments influenced plant WUE, despite equivalent production substrate $\Psi$. However, $\delta 13 \mathrm{C}$ was not correlated with $K\left(\Psi_{75}\right)$ or calculated integrated WUE ( $r=$ $-0.19, P=0.403$ and $r=0.08, P=0.635$, respectively).

Instantaneous measurements leaf $g_{\mathrm{s}}$ for the plants grown in the engineered substrates that underwent particle fractionation aligned in the same rank order with mean particle diameter. Instantaneous measures of transpiration showed a trend of increasing particle size resulting in decreased instantaneous transpiration $[P=0.052$ (Table 5)]. Tukey's honestly significant difference was unable to detect any treatment effects within instantaneous measures of $g_{\mathrm{s}}$, net photosynthesis, and transpiration. Instantaneous net photosynthesis, $g_{\mathrm{s}}$, and transpiration measurements were similar for plants grown in UPB compared with plants grown in PF4 and PF6, which were lower than the remaining treatments (Table 5). There was no 
Table 4. Plant growth and water status metrics of Hibiscus rosa-sinensis 'Fort Myers' grown in seven pine bark-based substrates including, unprocessed bark, four screened barks, and substrates comprised $6.3 \mathrm{~mm}$ bark amended with $35 \%$ (by volume) sphagnum peat (P35) or $40 \%$ (by volume) coir (C40). All plants produced while holding substrate matric potential between -50 and $-100 \mathrm{hPa}$.

\begin{tabular}{|c|c|c|c|c|c|}
\hline Substrate $^{z}$ & GI increase ${ }^{\mathrm{y}}(\mathrm{cm})$ & $\mathrm{LA}^{\mathrm{x}}\left(\mathrm{cm}^{2}\right)$ & Compactness $^{\mathrm{w}}\left(\mathrm{g} \cdot \mathrm{cm}^{-1}\right)$ & Total water vol used ${ }^{\mathrm{v}}(\mathrm{L})$ & $\delta^{13} C^{u}$ \\
\hline \multicolumn{6}{|l|}{ Control } \\
\hline \multicolumn{6}{|c|}{ Particle size fractionation } \\
\hline PF2 & $18.71 \mathrm{c}$ & $1,344 \mathrm{ab}$ & $0.2300 \mathrm{bc}$ & $7.72 \mathrm{ab}$ & $-27.19 \mathrm{a}$ \\
\hline PF4 & $20.48 \mathrm{c}$ & $1,286 \mathrm{ab}$ & $0.1883 \mathrm{c}$ & $6.14 \mathrm{ab}$ & $-27.07 \mathrm{a}$ \\
\hline PF6 & $18.81 \mathrm{c}$ & $1,065 \mathrm{~b}$ & $0.1708 \mathrm{c}$ & $5.31 \mathrm{~b}$ & $-27.24 \mathrm{a}$ \\
\hline \multicolumn{6}{|c|}{ Fiber additions } \\
\hline P35 & $30.54 \mathrm{ab}$ & $3,094 \mathrm{a}$ & $0.4225 \mathrm{a}$ & $12.69 \mathrm{ab}$ & $-27.94 \mathrm{a}$ \\
\hline $\mathrm{C} 40$ & $26.78 \mathrm{~b}$ & $2,897 \mathrm{a}$ & $0.3537 \mathrm{ab}$ & $12.05 \mathrm{ab}$ & $-28.29 \mathrm{a}$ \\
\hline$P^{\mathrm{q}}$ & 0.0566 & 0.7738 & 0.3253 & 0.6499 & 0.5621 \\
\hline
\end{tabular}

${ }^{\mathrm{z}}$ Stabilized, unprocessed pine bark (UPB) $<12.7 \mathrm{~mm}$; bark screened while at $65 \%$ moisture content $<2.3-\mathrm{mm}$ screen $(\mathrm{PF} 0), 2.3-4.0 \mathrm{~mm}(\mathrm{PF} 2)$, 4.0-6.3 mm (PF4), >6.3-mm screen (PF6); and PF4 amended (by volume) amended with fibrous materials including 35\% sphagnum peat (P35) and $40 \%$ coconut coir (C40).

${ }^{\mathrm{y}}$ Difference between growth index (GI) at the culmination and initiation of the study.

${ }^{\mathrm{x}}$ Total leaf area (LA) per plant at culmination of the study.

${ }^{\mathrm{w}}$ Shoot dry weight/shoot height at culmination of the study.

${ }^{\mathrm{v}}$ The total quantity of water that was provided to the individual containers throughout the study. Considered to be representative of total evapotranspiration over the same duration.

${ }^{\mathrm{u}}$ The difference in ${ }^{13} \mathrm{C}:{ }^{12} \mathrm{C}$ isotopes in newly mature foliar samples for each treatment and a Pee Dee Belemnite control sample.

${ }^{t}$ Means separated across all seven substrates (entire column) using Tukey's honestly significant difference, $\alpha=0.05$.

${ }^{\text {s}}$ Probability of linear relationship among particle fractionation substrates based on mean particle diameter.

${ }^{\mathrm{r}}$ Probability of quadratic relationship among particle fractionation substrates based on mean particle diameter.

${ }^{\mathrm{q}}$ Results of $t$ test to observe differences among the two fiber addition substrates.

difference in instantaneous WUE among the treatments $(P=0.340$, data not presented).

The calculated ET across the entire experiment followed a similar trend to the instantaneous measurements of transpiration, with PF0 using $\approx 12.5 \mathrm{~L}$ more water than PF6 (Table 4). There was a quadratic $\left(R^{2}=0.998\right)$ relationship between mean particle diameter and ET, and there was no difference between P35 and $\mathrm{C} 40(P=0.650)$. The water use in PF2, PF4, and PF6 substrates were all $<7.75 \mathrm{~L} /$ plant, the $\mathrm{P} 35$, C40, and PF0 used 12.05-18.85 $\mathrm{L} /$ plant, and the UPB $8.83 \mathrm{~L} /$ plant, continuing the trend of UPB producing the median value. Producing salable crops with under $20 \mathrm{~L} /$ plant $\mathrm{H}_{2} \mathrm{O}$ (and as low as $5.31 \mathrm{~L} /$ plant) could represent a significant reduction in water use in commercial container production.

There was no detectable difference in WUE (biomass accumulation/ET) with a mean of $3.18 \pm 0.18$ $\mathrm{g} \cdot \mathrm{L}^{-1}$ across all treatments. However, clear differences among treatments were observed when plotting ET vs. VPD (Fig. 3) after removing
Table 5. Mean $\pm \mathrm{SE}$ of instantaneous water status measurements made with a portable photosynthesis system $^{z}$ on Hibiscus rosa-sinensis 'Fort Myers' plants grown in seven bark-based substrates. Plants were irrigated such that substrate water potentials were maintained between -50 and -100 $\mathrm{hPa}$.

\begin{tabular}{|c|c|c|c|}
\hline Substrate $^{y}$ & $\frac{\text { Net photosynthesis }}{\left[\mathrm{CO}_{2}\left(\mu \mathrm{mol} \cdot \mathrm{m}^{-2} \cdot \mathrm{s}^{-1}\right)\right]}$ & $\frac{\text { Stomatal conductance }}{\left[\mathrm{H}_{2} \mathrm{O}\left(\mathrm{mol} \cdot \mathrm{m}^{-2} \cdot \mathrm{s}^{-1}\right)\right]}$ & $\frac{\text { Transpiration }}{\left[\mathrm{H}_{2} \mathrm{O}\left(\mathrm{mmol} \cdot \mathrm{m}^{-2} \cdot \mathrm{s}^{-1}\right)\right]}$ \\
\hline \multicolumn{4}{|l|}{ Control } \\
\hline UPB & $11.25 \pm 0.71^{x}$ & $0.16 \pm 0.05$ & $4.3 \pm 1.0$ \\
\hline \multicolumn{4}{|c|}{ Particle size fractionation } \\
\hline PF0 & $13.27 \pm 1.92$ & $0.33 \pm 0.10$ & $7.8 \pm 1.6$ \\
\hline PF2 & $14.81 \pm 1.92$ & $0.26 \pm 0.05$ & $6.9 \pm 1.0$ \\
\hline PF4 & $10.79 \pm 1.37$ & $0.19 \pm 0.05$ & $5.0 \pm 4.3$ \\
\hline PF6 & $12.30 \pm 0.33$ & $0.16 \pm 0.02$ & $4.6 \pm 1.2$ \\
\hline Linear $^{\mathrm{w}}$ & 0.5340 & 0.0617 & 0.0508 \\
\hline Quadratic $^{v}$ & 0.8205 & 0.1534 & 0.1405 \\
\hline \multicolumn{4}{|c|}{ Fiber additions } \\
\hline $\mathrm{P} 35$ & $17.26 \pm 0.69$ & $0.45 \pm 0.10$ & $9.1 \pm 1.2$ \\
\hline $\mathrm{C} 40$ & $16.93 \pm 2.84$ & $0.43 \pm 0.15$ & $8.9 \pm 2.5$ \\
\hline$P^{\mathrm{u}}$ & 0.9160 & 0.9437 & 0.9483 \\
\hline
\end{tabular}

${ }^{\mathrm{z}} \mathrm{LI}-\mathrm{COR}$ 6400XT (LI-COR Biosciences, Lincoln, NE) measurements with air temperature $=33.4{ }^{\circ} \mathrm{C}$, relative humidity $=40.5 \%$, and photosynthetic active radiation $=1300 \mu \mathrm{mol} \cdot \mathrm{m}^{-2} \cdot \mathrm{s}^{-1}$.

${ }^{\mathrm{y}}$ Stabilized, unprocessed pine bark (UPB; $<12.7 \mathrm{~mm}$ ); bark screened while at $65 \%$ moisture content $<2.3$-mm screen (PF0), 2.3-4.0 mm (PF2), 4.0-6.3 mm (PF4), >6.3-mm screen (PF6); and PF4 amended (by volume) amended with fibrous materials including $35 \%$ sphagnum peat (P35) and $40 \%$ coconut coir (C40).

$\mathrm{x}_{\text {SE }}$ of the mean.

${ }^{\text {w}}$ Probability of linear relationship among particle fractionation substrates based on mean particle diameter.

${ }^{\mathrm{v}}$ Probability of quadratic relationship among particle fractionation substrates based on mean particle diameter.

${ }^{\mathrm{u}}$ Results of $t$ test to observe differences among the two fiber addition substrates. 

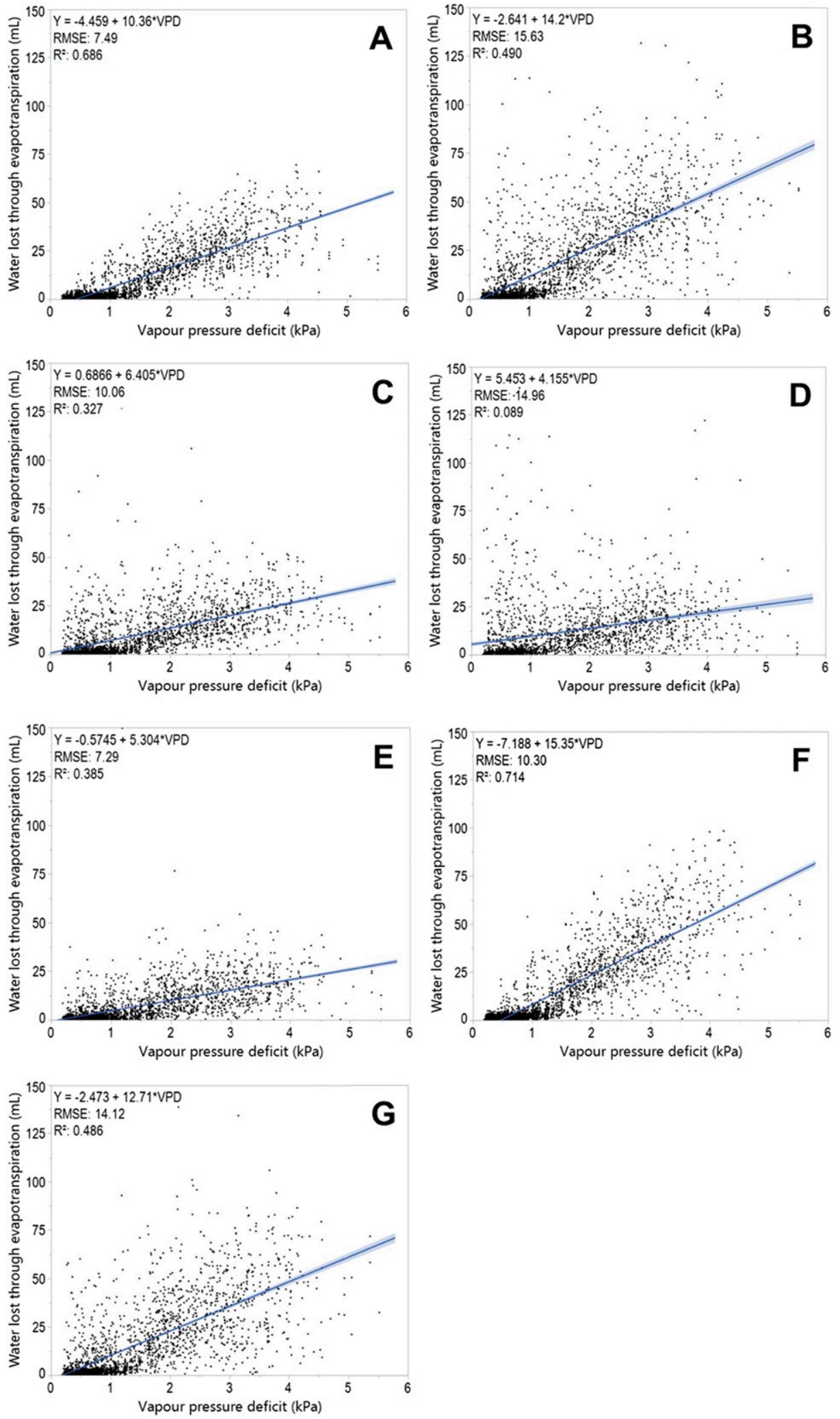

Fig. 3. Water loss through evapotranspiration vs. vapor pressure deficit for seven substrates including unprocessed pine bark [UPB (A)]; bark screened while at $65 \%$ moisture content $<2.3 \mathrm{~mm}$ [PF0 (B)], 2.3-4.0 mm [PF2 (C)], 4.0-6.3 mm [PF4 (D)], >6.3-mm screen [PF6 (E)]; and PF4 amended (by volume) amended with fibrous materials including $35 \%$ sphagnum peat [P35 (F)] and 40\% coconut coir (C40; G). Line represents the best linear fit and root mean square error (RMSE). values occurring at night when water loss was minimal. Assuming VPD as an estimator of evapotranspirational demand that is experienced equally among all replications, the slope of the linear fit was analyzed as the ability of the water in the substrate to be moved based on increased VPD. This measure is likely influenced by both the velocity water can be moved and the distance it can travel. The authors made an assumption that the stomata reacted to the VPD similarly, across all treatments as the regulation of transpiration by stomatal closure would be the primary resistance in this water continuum, based on instantaneous leaf $g_{\mathrm{s}}$ measures. The three substrates with the highest ET:VPD ratios were P35, $\mathrm{PF} 0$, and $\mathrm{C} 40$ (due to larger plants using more water), whereas the three substrates with the lowest substrate water conductance were PF4, PF6, and PF2. The ET:VPD slopes correlate with $K\left(\Psi_{75}\right)$ values $(r=0.73$, $P=0.064)$. The only inconsistency in the sequence of ET:VPD values compared with the sequence of $K$ $\left(\Psi_{75}\right)$ was UPB $\left(10.36 \mathrm{~L} \cdot \mathrm{kPa}^{-1}\right)$. The $K\left(\Psi_{75}\right)$ of UPB was larger than that of the C40; however, between the -50 to $-100 \mathrm{hPa}$ range the $K$ of the two substrates did intersect (Fig. 2), so although UPB had a higher $K$ $\left(\Psi_{75}\right)$, the $\mathrm{C} 40 \mathrm{~K}$ was larger as $\Psi$ approached $-100 \mathrm{hPa}$. It is likely that the increased $K$ of $C 40$ over the production range allowed water to move greater distances within the substrate. As $\Psi$ decreased (whether through surface evaporation or from root uptake), water moved with less inhibition from low pore connectivity or from less uniform pore size distributions possibly causing hysteretic restrictions in the substrates with increased production $K$. Plant size likely affects ET:VPD measures as the $\Delta \mathrm{GI}$ of the plants follows the same sequence across treatments as the $K\left(\Psi_{75}\right)$ and ET:VPD slopes. These are interrelated as increased $K$ allowed for greater growth, in which growth and subsequent increased plant size created a stronger sink that drove water uptake.

Plant water availability. Across the seven substrates, the linear relationship between $\mathrm{CC}_{\mathrm{E}}$ (maximum water holding capacity 
possible through overhead irrigation, termed effective CC) and porometer-measured CC were $<5 \%$ different (Fig. 4). Unprocessed pine bark and PF6 were the only substrates that were outside of the $9 \%$ confidence interval. This is in part due to the uniformity and connectivity of the pores in the five remaining

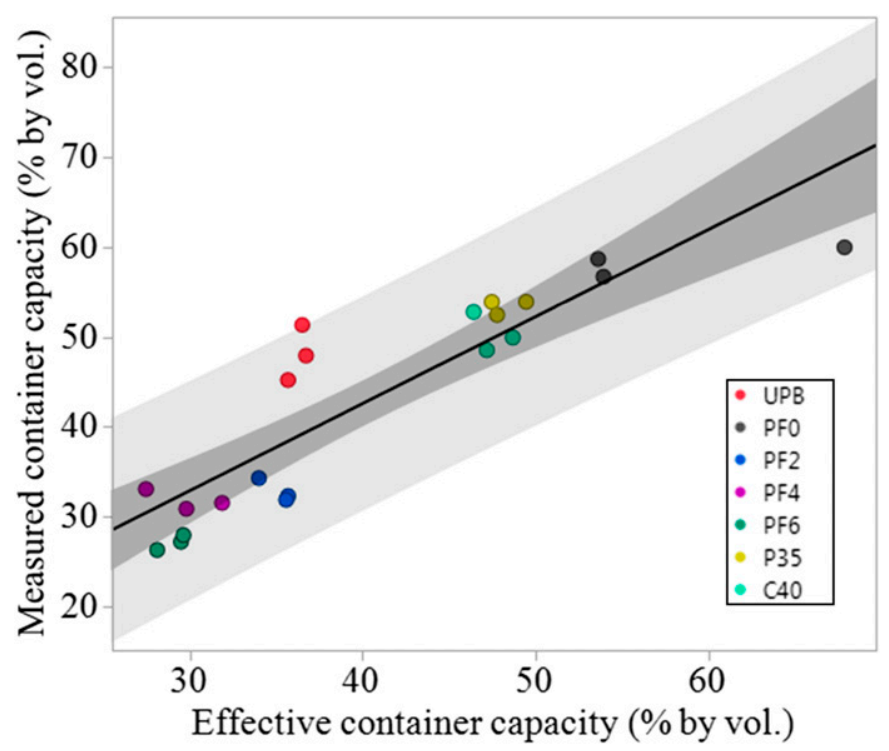

Fig. 4. Relationship between in situ effective container capacity for seven substrates including unprocessed pine bark (UPB); bark screened while at $65 \%$ moisture content $<2.3-\mathrm{mm}$ screen (PF0), 2.3-4.0 mm (PF2), 4.0-6.3 mm (PF4), $>6.3-\mathrm{mm}$ screen (PF6); and PF4 amended (by volume) amended with fibrous materials including $35 \%$ sphagnum peat (P35) and $40 \%$ coconut coir (C40). The dark-shaded region represents a $95 \%$ confidence interval, where the light-shaded region represents a $95 \%$ prediction interval. The equation for the line of fit is: measured container capacity $=0.97 \times$ effective container capacity +3.8 . Root mean square error for line of fit $=5.57 \%$ by volume and $R^{2}=0.79$.

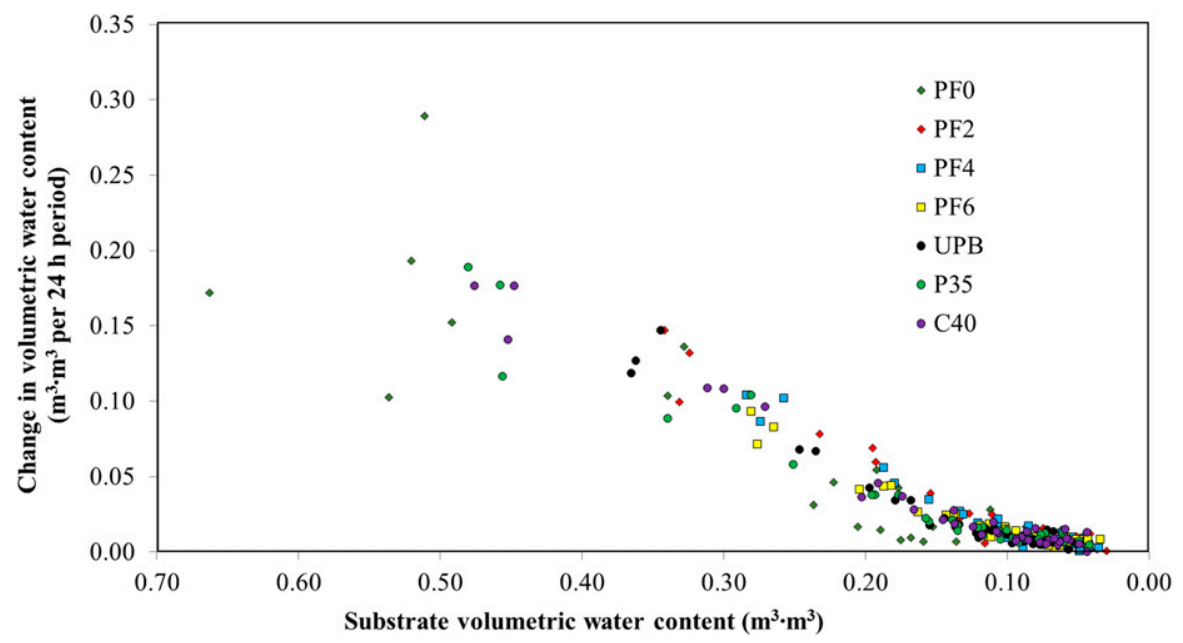

Fig. 5. The reduction in volumetric water content $(\theta)$ of seven experimental pine bark-based substrates used to produce Hibiscus rosa-sinensis. Seven substrates including unprocessed pine bark (UPB); bark screened while at $65 \%$ moisture content $<2.3 \mathrm{~mm}$ (PF0), 2.3-4.0 mm (PF2), 4.0-6.3 mm (PF4), >6.3-mm screen (PF6); and PF4 amended (by volume) amended with fibrous materials including 35\% sphagnum peat (P35) and 40\% coconut coir (C40). Substrates with fully rooted plants were watered to effective container capacity (maximum water holding capacity after overhead irrigation) before being allowed to dry past permanent wilt until the plant ceased withdrawing water from the substrate. Daily reduction in substrate $\theta$ were plotted against $\theta$ for each substrate to illustrate at what $\theta$ evapotranspiration shifts to evaporation primarily due to plant water uptake diminishing. experimental substrates mitigating the hysteretic effects of the substrate resulting in more uniform water distribution throughout the container when compared with UPB, thus, achieving in situ $\mathrm{CC}_{\mathrm{E}}$ more resembling the $\mathrm{CC}$ values measured in laboratory analyses via porometer.

Reduction in $\theta$ breakpoints from when transpiration was a primary driver of water loss to evaporation of primary water loss occurred from $0.14 \mathrm{~m}^{3} \cdot \mathrm{m}^{-3}$ (P35) to $0.08 \mathrm{~m}^{3} \cdot \mathrm{m}^{-3}$ (PF6) in the PF2, PF4, and PF6 (Fig. 5). The breakpoint for the plants grown in UPB was the median value among the seven substrates $\left(0.12 \mathrm{~m}^{3} \cdot \mathrm{m}^{-3}\right)$. The $\theta$ breakpoint occurred at $\Psi$ correbased on converting $\theta$ to $\Psi$ via Brooks and Corey models fit to MCC data (Fig. 1). The breakpoint of the UPB occurred at a $\Psi$ of $-0.39 \mathrm{MPa}$. The PF4 and PF6 substrates, which were ominated by large particles and subsequently large macropore volumes, had $\Theta$ breakpoints that occurred at $\Psi$ of -21.96 and $-11.94 \mathrm{MPa}$, respectively, based on the MCC models, when water loss was primarily from evaporation. These extreme values of $\Psi$ are not direct measures and as a result, it is not expected that these plants were able to withdraw water at -11.94 and $-21.96 \mathrm{MPa}$, and these values should be cautiously considered. Small reductions in substrate $\theta$ result in massive reductions in $\Psi$, at low $\Psi$, which results in nearly asymptotic nature of the MCC. Thus, with the coarse nature of the particles, relatively little water exists on particle surfaces, and $\Psi$ decreases to extremely low tensions with the loss of little water. This can be observed from $\Psi$ for -11.94 or $-21.96 \mathrm{MPa}$ to have $95 \%$ confidence intervals from -1.19 to -59.16 and -2.05 to -86.91 Pa, respectively (data not shown). Furthermore, we hypothesize the extreme low $\Psi$ reached by these substrates is a result of the pore distribution shifting the physical classification of water present in the substrate. The relatively small surface area and large macropore volume in PF4 and PF6 result in reduced hygroscopic (adsorbed to particles) and increased gravitational (moving from gravitational forces) water. Both hygroscopic and gravitational water are generally considered more unavailable to plants than capillary water (water held in pores). The drainage of the gravitational water and relatively little hygroscopic and capillary water results in substrates reaching very low $\Psi$ more rapidly. The particle fractionation substrates, which resulted in a shift in pore sizes from gravitational to hygroscopic (PF2 and PF0), had larger proportions of water unavailable. However, there was increased water present, which allowed plants to continue to grow and use water, as the gravitational water readily drains from the substrates.

Plants produced in PF4 and PF6 may also have developed stress memory as a result of the low substrate water volumes provided throughout the study (Bruce et al., 
2007). Although substrate $\Psi$ was kept constant, the PF4 and PF6 had lower volumes of water within the container (Table 2). FletaSoriano and Munne-Bosch (2016) recently reviewed many aspects of drought stress memory in plants, and discussed the ability of a plant to alter its physiology over the course of a season, within minutes or even seconds as a result of nonoptimal water conditions. The resulting reduced total water quantities that were applied to these two treatments to maintain $\Psi$ between -50 and $-100 \mathrm{hPa}$, as well as reduced $K$ restricting plant water access, may have caused the plants in these substrates to alter their water uptake or transpirational mechanisms. This is similar to the practice of "deficit irrigation" which is often being used more in agronomic and fruit production to combat water restrictions (Fereres and Soriano, 2007), and has been described for containerized nursery crops (Davies et al., 2016).

Because P35 was considered to have produced the best growing plants based on morphological data (Table 4) and possessed the highest $K$ values in the WBC range, we surmise that better growth was a result of more uniform access of plants to water throughout the container volume, and the ability of the substrate to deliver water easily across a distance when $\Psi$ decreased. As a result, we hypothesize that increased substrate $K$ within the WBC range may result in a quicker production period reaching salability in less time. Plants herein were grown under optimal conditions; however, the addition of peat did not result in sustained plant vigor at low $\Psi$ to the same degree as the other engineered substrates in this research. Therefore, it is possible that the high $K$ in the $\mathrm{P} 35$ allowed plants to remove water uniformly from the entirety of the substrate. Consequently, it is possible that other substrates were able to sustain plant vigor via a small hydrated region in the substrate that may not have been able to be used until direct contact with roots occurred.

\section{Conclusion}

Unsaturated $K$, when water kept between -50 and $-100 \mathrm{hPa}$ (WBC), can be increased by decreasing the mean particle size of bark or with the addition of peat to a coarse bark. Increasing unsaturated $K$ within the production range $(-50$ to $-100 \mathrm{hPa}$ substrate water potential) resulted in increased plant growth. No correlation between $K_{\mathrm{s}}$ and unsaturated $K$ (within the optimal production range) was observed; therefore, unsaturated $K$ should be used to make informed decisions as production $K$ affects crop morphology and ability of the plant to access water.

Hibiscus grown in substrates with higher $K\left(\Psi_{75}\right)$ showed greater growth and vigor while producing the more desirable (marketable) crops. Water became inaccessible to plants grown in the peat-amended bark at higher $\Psi(-0.6 \mathrm{MPa})$ than all experimental substrates except for UPB. The particle fractionation and the addition of coir to the coarse bark resulted water held in substrates to reach $\Psi<-1.5 \mathrm{MPa}$ before shifts in trends of $\theta$ reduction. Thus, the authors believe that in optimal growing conditions, the addition of peat will result in improved water distribution and delivery to plant roots. Although, the addition of coir, while improving aeration and retaining sufficient water in the optimal growing $\Psi$ range, will allow for higher proportions of water to be used at low $\Psi$ in a water deficit event. Moreover, as the relationship between substrate $K$ as $\Psi$ is dynamic, additional research involving measurements of substrate $K$ at $\Psi$ breakpoints where plants stop removing water from substrates is needed to understand the effect of substrate $K$ on water availability.

\section{Literature Cited}

Argo, W.R. 1998. Root medium physical properties. HortTechnology 8:481-485.

Bayer, A., I. Mahbub, M. Chappell, J. Ruter, and M.W. van Iersel. 2013. Water use and growth of Hibiscus acetosella 'Panama Red' grown with a soil moisture sensor-controlled irrigation system. HortScience 48:980-987.

Beeson, Jr., R.C., M.A. Arnold, T.E. Bilderback, B. Bolusky, S. Chandler, H.M. Gramling, J.D. Lea-Cox, J.R. Harris, P.J. Klinger, H.M. Mathers, J.M. Ruter, and T.H. Yeager. 2004. Strategic vision of container nursery irrigation in the next ten years. J. Environ. Hort. 22:113-115.

Beeson, Jr., R.C. and T.H. Yeager. 2003. Plant canopy affects sprinkler irrigation application efficiency of container-grown ornamentals. HortScience 38:1373-1377.

Bilderback, T., C. Boyer, M. Chappell, G. Fain, D. Fare, C. Gilliam, B. Jackson, J. Lea-Cox, A. LeBude, A. Niemiera, J. Owen, J. Ruter, K. Tilt, S. Warren, S. White, T. Whitewell, R. Wright, and T. Yeager. 2013. Best management practices: Guide for producing nursery crops. Southern Nursery Assn., Acworth, GA.

Brooks, R.H. and A.T. Corey. 1964. Hydraulic properties of porous media. Colorado State Univ., Hydrol. Paper 5.

Bruce, T.J., M.C. Matthes, J.A. Napier, and J.A. Pickett. 2007. Stressful "memories" of plants: Evidence and possible mechanisms. Plant Sci. 173:603-608.

Campbell, G.S. and M.D. Campbell. 1982. Irrigation scheduling using soil moisture measurements: Theory and practice. Adv. Irr. $1: 25-42$.

Caron, J. and D.E. Elrick. 2005. Measuring unsaturated hydraulic conductivity of growing media with a tension disk. Soil Sci. Soc. Amer. J. 69:783-793.

Caron, J., S. Pepin, and Y. Periard. 2014. Physics of growing media in a green future. Acta Hort. 1034:309-317.

Chappell, M., S.K. Dove, M.W. van Iersel, P.A. Thomas, and J. Ruter. 2013. Implementation of wireless sensor networks for irrigation control in three container nurseries. HortTechnology 23:747-753.

Chartzoulakis, K., B. Noitsakis, and I. Therios. 1993. Photosynthesis, plant growth and dry matter distribution in kiwifruit as influenced by water deficits. Irr. Sci. 14:1-5.

da Silva, F.F., R. Wallach, and Y. Chen. 1993. Hydraulic properties of sphagnum peat moss and tuff (scoria) and their potential effects on water availability. Plant Soil 154:119-126.

Davies, M.J., R. Harrison-Murray, C.J. Atkinson, and O.M. Grant. 2016. Application of deficit irrigation to container-grown hardy ornamental nursery stock via overhead irrigation, compared to drip irrigation. Agr. Water Mgt. 163:244-254.

de Boodt, M. and O. Verdonck. 1972. The physical properties of substrates in horticulture. Acta Hort. 26:37-44.

Drzal, M.S., W.C. Fonteno, and K.C. Cassel. 1999. Pore fraction analysis: A new tool for substrate testing. Acta Hort. 48:43-54.

Egilla, J.N., F.T. Davies, Jr., and T.W. Button. 2005. Drought stress influences leaf water content, photosynthesis, and water-use efficiency of Hibiscus rosa-sinensis at three potassium concentrations. Photosynthetica 43:135-140.

Farquhar, G.D., J.R. Ehleringer, and K.T. Hubick. 1989. Carbon isotope discrimination and photosynthesis. Annu. Rev. Plant Physiol. Plant Mol. Biol. 40:503-537.

Fereres, E. and M.A. Soriano. 2007. Deficit irrigation for reducing agricultural water use. J. Expt. Bot. 58:147-158.

Fields, J.S. 2013. Hydrophysical properties and hydration efficiency of traditional and alternative greenhouse substrate components. North Carolina State Univ., Raleigh, NC, MS Diss.

Fields, J.S., W.C. Fonteno, and B.E. Jackson. 2014a. Hydration efficiency of traditional and alternative greenhouse substrate components. HortScience 49:336-342.

Fields, J.S., W.C. Fonteno, B.E. Jackson, J.L. Heitman, and J.S. Owen, Jr. 2014b. Hydrophysical properties moisture retention, and drainage 
profiles of wood and traditional components for greenhouse substrates. HortScience 49:827-832.

Fields, J.S., J.S. Owen, Jr., L. Zhang, and W.C. Fonteno. 2016. Use of the evaporative method for determination of soilless substrate moisture characteristic curves. Scientia Hort. 211:102-109.

Fleta-Soriano, E. and S. Munne-Bosch. 2016. Stress memory and the inevitable effects of drought: A physiological perspective. Front. Plant Sci. 7:143.

Fonteno, W.C. 1993. Problems and considerations in determining the physical properties of horticultural substrates. Acta Hort. 342:197204.

Fonteno, W.C. and C.T. Harden. 2010. North Carolina State University horticultural substrates lab manual. 6 Dec. 2017. <https://projects. ncsu.edu/project/hortsublab/pdf/porometer_manual.pdf $>$.

Fulcher, A. and T. Fernandez. 2013. Sustainable nursery irrigation management series: Part I. Water use in nursery production. Univ. Tennessee Bul. W287.

Fulcher, A., A.V. LeBude, J.S. Owen, Jr., S.A. White, and R.C. Beeson. 2016. The next ten years: Strategic vision of water resources for nursery and greenhouse producers. HortTechnology 26:121-122.

Heiskanen, J. 1999. Hydrological properties of container media based on sphagnum peat and their potential implications for availability of water to seedlings after outplanting. Scand. J. For. Res. 14:78-85.

Hunt, A.G., R.P. Ewing, and R. Horton. 2013. What's wrong with soil physics? Soil Sci. Soc. Amer. J. 77:1877-1887.

Jury, W.A. and R. Horton. 2004. Soil physics. Wiley, Hoboken, NJ.

Kenney, J.F., N.L. Barber, S.S. Hutson, K.S. Linsey, J.K. Lovelace, and M.A. Maupan. 2009. Estimated use of water in the United States in 2005. U.S. Geological Serv. Circ. 1344.

Londra, P.A. 2010. Simultaneous determination of water retention curve and unsaturated hydraulic conductivity of substrates using a steady-state laboratory method. HortScience 45:1106-1112.

Mathers, H.M., T.H. Yeager, and L.T. Case. 2005. Improving irrigation water use in container nurseries. HortTechnology 15:8-12.

Milks, R.R., W.C. Fonteno, and R.A. Larson. 1989. Hydrology of horticultural substrates II: Predicting properties of media in containers. J. Amer. Soc. Hort. Sci. 114:53-56.

Million, J., T. Yeager, and J. Albano. 2007. Consequences of excessive overhead irrigation on runoff during container production of sweet viburnum. J. Environ. Hort. 25:117-125.
Million, J.B., T.H. Yeager, and J.P. Albano. 2010. Evapotranspirationbased irrigation scheduling for container-grown Viburnum odoratissimum (L.) Ker Gawl. HortScience 45:1741-1746.

Mualem, Y. 1976. A new model for predicting hydraulic conductivity of unsaturated porous media. Water Resources Res. 12:513-522.

Naasz, R., J.C. Michel, and S. Charpentier. 2005. Measuring hysteretic hydraulic properties of peat and pine bark using a transient method. Soil Sci. Soc. Amer. J. 69:13-22.

O'Meara, L., M.R. Chappell, and M.W. van Iersel. 2014. Water use of Hydrangea macrophylla and Gardenia jasminoides in response to a gradually drying substrate. HortScience 49:493-498.

Pallardy, S.G. 2008. Physiology of woody plants. 3rd ed. Elsevier, San Diego, CA.

Pustjarvi, V. and R.A. Robertson. 1975. Physical and chemical properties, p. 23-38. In: D.W. Robinson and J.G.D. Lamb (eds.). Peat in horticulture. Academic Press, London, UK.

Raviv, M. and J.H. Lieth. 2008. Soilless culture theory and practice. Elsevier, San Diego, CA.

Raviv, M., R. Wallach, A. Silber, S. Medina, and A. Krasnovsky. 1999. The effect of hydraulic characteristics of volcanic materials on yield of roses grown in soilless culture. J. Amer. Hort. Sci. 124:205-209.

Richards, D., M. Lane, and D.V. Beardsell. 1986. The influence of particle-size distribution in pinebark: Sand: Brown coal potting mixes on water supply, aeration and plant growth. Scientia Hort. 29:1-14.

Stephens, D.B. and K.R. Rehfeldt. 1985. Evaluation of closed-form analytical models to calculate conductivity in a fine sand. Soil Sci. Soc. Amer. J. 49:12-19.

U.S. Department of Agriculture. 2015. Census of agriculture, 2009. Census of horticultural specialties. 15 Dec. 2015. <http://www. agcensus.usda.gov/Publications/2012/Online_Resources/Census_ of_Horticulture_Specialties/HORTIC.pdf $>$.

van Iersel, M.W. and K.S. Nemali. 2004. Drought stress can produce small but not compact marigolds. HortScience 39:1298-1301.

Wallach, R., F.F. da Silva, and Y. Chen. 1992. Hydraulic characteristics of tuff (Scoria) used as a container medium. J. Amer. Soc. Hort. Sci. 117:415-421.

Warsaw, A.L., R.T. Fernandez, B.M. Cregg, and J.A. Andersen. 2009. Container-grown ornamental plant growth and water runoff nutrient and volume under four irrigation treatments. HortScience 44:15731580 . 